\title{
CrimRxiv
}

\section{One gang dies, another gains? The network dynamics of criminal group persistence}

Marie Ouellet ${ }^{1}$, Martin Bouchard ${ }^{2}$, Yanick Charette ${ }^{3}$

${ }^{1}$ Georgia State University, ${ }^{2}$ Simon Fraser University, ${ }^{3}$ Université Laval

Published on: Sep 16, 2020

DOI: 10.21428/cb6ab371.0f3fbca8

License: Creative Commons Attribution 4.0 International License (CC-BY 4.0). 


\section{ABSTRACT}

What leads a minority of criminal groups to persist over time? Although most criminal groups are characterized by short life spans, a subset manage to survive over extended periods. Contemporary research on criminal groups has been primarily descriptive and static, leaving important questions on the correlates of group persistence unanswered. Drawing from competing perspectives on the relationship between cohesion and group persistence, the current study applies a longitudinal approach to examine the network dynamics influencing the life span of criminal groups. Nine years of official data on the criminal and social networks of gang-associates in Montreal is used to delineate criminal group boundaries and examine variation in group duration. Our statistical approach simultaneously considers within and between-group attributes to isolate how groups' cohesion as well as their embeddedness in the wider gang structure impacts survival. Results show that group survival is a function of their cohesion and embeddedness. Yet, the relationship is not direct but moderated by group size. Whereas, large groups that adopt closed structures are more likely to persist, small groups' survival depends on less cohesive and more versatile structures. The discussion considers the impact of these findings for the continued understanding of group trajectories.

Nearly a century ago, Thrasher (1927) detailed the transience of criminal groups across more than 1,000 street gangs; an appraisal that has since become familiar in the criminological literature (Reuter, 1983; Sarnecki, 2001; Short and Strodtbeck, 1965; Spergel, 1966; Warr, 1996). As a whole, this literature documents the impermanent and unstable nature of criminal groups, finding that, while a subset of groups persist over time, the majority are characterized by short life-spans. The ephemeral nature of groups has been well established across time and space. In Stockholm, members of criminal groups frequently switched affiliation, precluding the formation of stable entities (Sarnecki, 2001). Similarly, in the United States, cooffending groups were found to rarely survive beyond a single criminal event (Warr, 1996). Even among a sample of active gangs in Chicago, few groups were observed across all time periods (Papachristos, 2009).

Research has shown that criminal groups end at a high rate, but fundamental questions on what leads the majority to desist, and only a subset to persist remain unclear. An understanding of these questions has important implications, with continuity in such groups found to be associated with continued, serious criminal 
activity (Melde and Esbensen, 2014; Pyrooz et al., 2016). Theoretically, the question also has relevance for existing perspectives that have advanced competing claims for the properties that attenuate or enhance a group's longevity. In general, dominant perspectives contend that a group's cohesion moderates its duration. However, differences emerge in regard to the direction of this relationship. On one side, prominent gang scholars have suggested that groups' cohesion is positively associated with their survival. In its most basic form, these scholars have argued that cohesion promotes group survival, as it enhances a group's ability to retain existing membership. This perspective is reflected in earlier assessments of criminal group duration (e.g. Jansyn, 1996; Klein and Crawford, 1967). It can also be found underlying local, national, and international policing efforts, with targeting strategies often aimed at destabilizing a group's cohesion, thereby disrupting interactions and criminal group activity (Bright, 2015; Hennigan and Sloane, 2013).

On the other side are scholars that have advanced the thesis that cohesion restricts a group's duration. This body of research has highlighted that group survival requires two competing obligations: the need to recruit new members, and the need to retain existing members. From this perspective, increases in cohesion can help retain membership, but too much cohesion can hinder a group's ability to bring in new recruits, leading to stagnation, and its eventual demise (see Shi et al., 2017). At the core of this hypothesis is the recognition that groups are embedded in a larger social environment and must compete with other organizations to recruit and retain membership. Thus, survival depends on creating a balance between keeping open channels for recruits, while creating the necessary cohesion to maintain membership. While this thesis has primarily been advanced in the literature on social movements and voluntary organizations, it may apply equally to criminal groups, that are often spatially concentrated in dense, urban areas (Curry and Spergel, 1988; Short and Strodtbeck, 1965; Vigil, 1988; 2002), and frequently interact between one another (e.g. Descormiers and Morselli, 2011; Fleisher, 2005; Tenti and Morselli, 2014).

Absent from these competing perspectives on cohesion and persistence are crosscomparisons using empirical data on criminal groups. Much of the literature on criminal group persistence and cohesion draws inferences from individual-level studies. For instance, Pyrooz, Sweeten, and Piquero (2013) showed that embedded gang members are more likely to delay their desistance from the gang, as compared to their less embedded counterparts. Among a sample of general co-offenders, Charette and Papachristos (2017) found similar results, showing that network embeddedness, as measured by connectivity, increased stability in co-offending relations. Yet, 
substantially less attention has been paid to the group-level mechanisms linking cohesion and group persistence, an omission that Klein (2005) attributes to the longstanding lack of group-level data. Individual-level studies represent important contributions for understanding individual correlates of group-stability; however, extrapolating individual characteristics to the group-level may confound effects where what is true for individuals does not equally apply to the aggregate. As such, these contradictory perspectives remain largely untested.

Taking a cue from recent studies that have shown the relative utility of using network methods to address the crime group problem (Calderoni, Brunetto, and Picardi, 2017; Kreager, Rulison, and Moody, 2011; Lantz and Hutchison, 2015; Malm, Bichler, and Nash, 2011), the current study examines the factors that allow a subset of criminal groups to persist. We rely on nine years of police records that detail the criminal and social interactions of gang-associates in Montreal, Canada to delineate group boundaries using a network approach. We then examine variation in groups' ability to regenerate over time, defining a group's survival based on stable sets of membership who link the group across time periods (e.g. Palla, Barabási, and Vicsek, 2007; Sarnecki, 2001). Our analysis aims to understand the network processes influencing the life span of criminal groups, focusing on groups' cohesion, as well as their embeddedness within the wider criminal context, as predictors of group persistence.

\section{COHESION AND GROUP PERSISTENCE}

While some criminal groups band and disband within the span of a single criminal event (e.g. Warr, 1996) others have been documented to survive more than half a century (e.g. the Gangster Disciples, Papachristos, 2009; Perkins, 1987). Most criminal groups fall into the former category, but important attention has been devoted to studying the latter. For instance, ethnographies tend to oversample groups that survive longer periods (e.g. see Klein, 2005), and case studies tend to focus on the more active, 'successful' organizations. Thus, while gangs are primarily ephemeral, much of what we know relies on a handful of persistent groups. These studies have identified cohesion as central to understanding group processes (e.g. Decker, 1996; Densley, 2015; Hennigan and Spanovic, 2012; Hughes, 2013; Klein, 1971; Sanchez-Jankowski, 1991; Short and Strodtbeck, 1965; Vigil, 1988), influencing group violence (Hughes, 2013), resilience to interdictions (Vargas, 2014), and the ability to carry out complex crimes (Tenti and Morselli, 2014).

Yet, the role of cohesion in explaining criminal group persistence remains disputed. In general, accounts of group persistence contend that groups' structural features may 
be invoked to understand variation in longevity. For some, dense, cohesive groups promote the likelihood of survival. Proponents of this perspective, point to the positive relationship between cohesion and stability. Cohesion promotes solidarity, enhances the internalization of criminal norms (e.g. Collins, 1988; Decker and Curry, 2002) increases compliance, and decreases in-fighting - thus fostering stability in members and member relations over time (see Hagedorn, 1994; Spergel, 1995). According to these scholars, individuals embedded in dense, criminal groups experience a higher 'cost' of disengaging, meaning that the expected returns from remaining a member (e.g. sense of belonging, source of identity) are likely to outweigh the expected returns from desisting. From this perspective, individuals belonging to a tightly cohesive group have more to lose than others.

For other scholars, cohesive groups are primed to fail - decreasing available opportunities, and increasing risks. In illicit contexts, where criminal groups are subject to both internal (e.g. aging out, member conflict) and external (e.g. arrest, incarceration) forces of membership loss, group survival may depend heavily on recruiting new members to perpetuate the group over time. Scholars who question a positive relationship between cohesion and group longevity point to the costs of cohesion. The costs of cohesion come in two main forms: the first is in the capacity to recruit. Lacking external connections, cohesive groups are less equipped to reach out and bring in new members when old ones are removed, defect, or are kicked out. The second cost comes in the group's ability to provide members returns for their membership. Previous research has suggested that cohesive groups may have access to fewer and less lucrative criminal opportunities, as compared to those who branch out beyond their immediate membership (e.g. Bouchard and Morselli, 2014; Tremblay, 1993).

In many ways, the divide between scholarly assessments of cohesion and group survival echo early arguments that outline the two primary mechanisms by which social networks create social capital. Early sociological scholars defined complementary mechanisms whereby group's structural features facilitated beneficial group outcomes. In his seminal work, Coleman $(1988,1990)$ outlined the benefits of cohesion for promoting group efficiency, with trusted relationships creating the stability necessary to efficiently communicate and perform tasks. Whereas, Burt (1992, 2005) focused on the benefits of non-cohesive (i.e. non-redundant structures), where not all members were connected (also see Granovetter, 1973). Less cohesive structures were found to promote innovation and achievement, by virtue of ties that connect otherwise unconnected actors, providing differential access to opportunities and 
resources (Burt, 1992, 2005). These influential works highlighted how a group's organization can lead to different outcomes in terms of their performance. Whereby cohesion promoted homogeneity and efficiency, non-redundant structures enhanced growth and innovation. However, less understood is how cohesive (or non-cohesive) structures enable a group to persist over time. Here, we elaborate on evidence for both perspectives, focusing on studies that have examined the role of cohesion in influencing group duration.

\section{RETURNS OF COHESION FOR GROUP SURVIVAL}

The most consistent evidence pertaining to the role of cohesion in promoting group survival is in the area of group membership. Scholars who suggest that cohesion promotes longevity primarily point to its role in retaining existing membership. Early ethnographic, and more recent empirical research has indicated that gang members who are embedded within the gang, particularly those with a high number of ties to other gang members, are more likely to remain with the group than members on the periphery (Horowitz, 1983; Klein, 1971; Lucore, 1975; Pyrooz, Sweeten, and Piquero, 2013). An analysis of gang members from the Pathways to Desistance study provides one of the most prominent demonstrations of this relationship. Relying on a sample of 226 youth, Pyrooz, Sweeten, and Piquero (2013: 241) followed individuals' status as gang members and their degree of embeddedness within the gang over a five-year period. Defined as being "immersed in an enduring deviant network" and operationalized as the degree of contact and activity within the gang, embeddedness was positively associated with the duration of gang membership. In other words, gang embeddedness delayed defection. A similar finding was reported by Charette and Papachristos (2017) who examined the stability of co-offending relationships across a sample of more than 8,000 offenders over an eight-year period. They found that cooffenders who were more embedded in their offending network (shared a co-offender in common) were more likely to continue co-offending with the same partners. Consistent with individual-level findings, groups with more cohesive structures have also been suggested to endure for longer periods. In their study of gangs in Los Angeles, Klein and Crawford (1967) contend that external conflict provides the main source of groups' cohesion, and that this cohesion, in turn, drives groups' survival (also see Fleisher, 1998). Summarizing this appraisal, the authors' state: "only rarely does a gang develop a sufficient number of internally-oriented systems to perpetuate itself in the absence of external pressures" (Klein and Crawford, 1967: 66). Just as they suggest that external conflicts are a main source of cohesion, they similarly assert that cohesion is a condition for groups' survival. Providing empirical support for this link, 
Klein and Crawford (1967) map the interactions across gang members in Los Angeles, relying on contact reports collected by gang workers that provided information on: 1) gang members; and 2) the other members s/he was most frequently seen with. From these reports, they identified 576 gang members who could be clustered into four cliques based on their patterns of interactions. Findings showed that the groups with higher internal cohesion - a greater number of ties to other members within their clique - had higher rates of delinquency and were also among those that survived for longer periods as compared to the other cliques (Klein and Crawford, 1967: 74).

Similar conclusions were drawn by Jansyn (1966) in his ethnographic research of a Chicago gang. Relying on more than a year of daily attendance records of gang members at a regular 'hang-out', Jansyn (1966) found that when the group's solidarity fell to particularly low levels, the remaining active members increased initiations of criminal activity with the purpose of re-instigating the gang. Despite identifying different sources of cohesion - internal from external - the overall implication of Jansyn's (1966) and Klein and Crawford's (1967) studies were consistent with the view that cohesion enhances group persistence. Cohesion is perceived as a key mechanism to retain members interested, and active in the gang for longer periods. However, the conclusions of these authors rested on a small number of groups, and were based on relatively short observation periods, raising concerns about whether results capture the natural cycle of group longevity versus processes tied to their internal structure (see Klein, 2005).

\section{COSTS OF COHESION FOR GROUP SURVIVAL}

In contrast, scholars who contend cohesion hurts group longevity point to its tendency to hamper a group's ability to recruit. Cohesive groups, by definition, primarily interact with other members, creating redundant network structures where everyone is connected to everyone else. Not only are these types of structures less amenable to recruitment, but they may also hinder groups' capacities to generate criminal opportunities, especially in the long term. From this perspective, groups that survive are groups that have access to a pool of potential recruits, and generate either tangible, or intangible benefits for its members (ideally, both).

The theoretical underpinnings of the link between non-redundant network structures and beneficial outcomes can be found in the seminal work of Burt (1992). In his theory of structural holes, Burt (1992) highlights the advantages that accrue to individuals who bridge otherwise unconnected others. Individuals who are structurally positioned between actors who are not themselves connected can benefit from the novel 
information or resources that such a structure provides, including control benefits to leverage access to disconnected actors. Reaching beyond immediate group members, individuals rich in structural holes are better positioned to access a diverse set of opportunities, skills, and resources. In contrast, individuals embedded in redundant networks, are exposed to the same set of individuals and resources within the group, reinforcing existing views and limiting access to novel opportunities, ideas, and growth. Empirical support for this argument has been found in criminal contexts. For instance, focusing on a sample of incarcerated offenders, Morselli and Tremblay (2004) demonstrated that individuals within non-redundant network structures were more likely to reap higher criminal returns.

Although his theory of structural holes was initially applied to examine individual-level outcomes, Burt (2005) extended its application to the group-level. Specifically, he argued that just as individual-performance was associated with being positioned as a broker, group-performance was associated with forming bridges across groups. Building on this argument, he further suggested that returns were greatest for groups that not only formed connections with other groups, but also adopted cohesive, internal structures. He contends that groups are better able to profit from their brokerage positions if knowledge and opportunity benefits can more efficiently be disseminated across members. Empirically demonstrating this link, Burt (2004) examined the performance of managers, finding that the same benefits that accrued to individuals positioned as brokers, also assisted in promoting beneficial outcomes for groups.

Shi et al. (2017) recently provided one of the first empirical demonstrations of the relationship between a group's cohesion and longevity. The authors argued that a group's survival requires creating a balance between two competing structures: closed, cohesive structures to retain existing membership, and connections beyond a group's immediate membership to facilitate new recruitment. The authors formalized this argument through an agent-based model that examined the degree to which members interacted within the organization, as well as the time and energy demands imposed by the organization (to model constraints on spending time with other competing organizations) influenced the group's duration. Findings showed that high cohesion protected the group from defection, and thus survival in the short-term; however, that a group's long-term survival depended on its ability to regenerate and reach beyond existing membership to replenish its ranks when defection occurred. These findings built off a large body of sociological literature on social movements and voluntary groups that have shown that cohesion shapes the retention of members 
(Coser, 1974; Kanter, 1972), the degree to which members defect to competing organizations (McPherson, Popielarz, and Drobnic, 1992), and opportunities for recruitment (Rochford, 1982; Snow, Zurcher, and Ekland-Olson, 1980).

These studies emphasize that any discussion of group persistence should focus on the role of cohesion in shaping both the recruitment and desistance processes. Yet, the literature on criminal groups (at the group-level) has primarily been dominated by studies that emphasize groups' abilities to maintain membership, rather than the processes associated with replenishing membership. An important omission considering the relatively high turnover (estimated at 36\% annually, Pyrooz and Sweeten, 2015), and short duration of gang membership (Pyrooz, Sweeten, and Piquero, 2013). That is not to say an important body of work on recruitment processes has not been developed. In fact, some of the core developments in the gang literature has focused on the individual and contextual factors that influence selection processes into gangs (e.g. Decker and van Winkle, 1996; Densley, 2012). These studies have shaped our understanding of gang processes; however, the discussion often focuses on individual-level selection mechanisms. Studying persistence at the group-level requires a shift from the typical focus of recruitment and (especially) desistance from the individual to the group. From this perspective, group survival depends on a combination of individual- and group-level forces that combine to extend or shorten a group's life cycle.

Despite this gap between theoretical perspectives and empirical studies, anecdotal accounts suggest that criminal groups that forego cohesion in favor of more versatile structures accrue important benefits that may shape group survival. For instance, Bouchard and Morselli (2014) argue that groups that collaborate beyond their immediate membership, increase the number of available opportunities and overall success of the group. From this perspective, connections to external groups provide structures ripe for opportunistic and instrumental crimes. Given the potential risks associated with co-offending (McCarthy, Hagan, and Cohen, 1998; Nguyen and McGloin, 2013; Tremblay, 1993), social structures that are primed for more lucrative opportunities may be more likely to attract members, accruing benefits in return for their membership.

These same contentions can also be found in discussions of the role of age-graded structures in promoting group survival. Although the link between age-graded and noncohesive structures is not made explicit, Klein and Maxson (2006) suggest that agegraded structures promote survival in much the same way as scholars who emphasize 
the benefits of non-cohesive structures for survival, arguing that groups that branch out beyond their membership and provide more attractive opportunities are more likely to survive. Specifically, Klein and Maxson (2006) outline two interrelated mechanisms by which age-graded structures enhance survival. First, age-graded structures provide the group with self-regeneration capacities; as criminal groups mature, older members age out, are killed or detained, age-graded membership allows the group to reproduce and maintain a supply of members to replace them. Second, age-graded structures provide a succession order for members already embedded in the group. Younger members have a motive to remain, as they graduate or are promoted to higher status (Miller, 1974; also see Curry, Decker, and Egley, 2002). These studies suggest parallels with the cohesion literature, also contending that branching out beyond membership may be beneficial for group persistence. However, neither have directly tested the link between less cohesive structures and criminal group survival.

\section{CURRENT STUDY}

The current study applies a longitudinal approach to examine the network dynamics influencing the life span of criminal groups. Using nine years of official data on the criminal and social networks of gang-associates in Montreal, Quebec, we first delineate gang boundaries using network methods, and then examine variation in groups' survival over time. Our statistical approach simultaneously considers within and between-group attributes to isolate how groups' cohesion, as well as their embeddedness in the wider gang structure impacts survival. The approach contributes to the literature on criminal groups in three key ways.

First, this study addresses the untested hypothesis that criminal group persistence is associated with a group's cohesion. Although extant research suggests that cohesion moderates a group's longevity, the direction of this relationship remains unclear, with far more research on persistence at the individual-level characterizing the literature. Here, we rely on a network approach to directly test how a group's cohesion influences persistence. An understanding of group persistence has broad social implications. It can help provide a more in-depth understanding of the life cycle of groups and offending behavior. For instance, the continuation of groups complicates efforts to estimate changes in crime rates, following the removal of individual group members through incarceration (e.g. Andresen and Felson, 2010). An understanding of group persistence can assist in understanding the group-level mechanisms that perpetuate criminal behavior beyond the removal of any member. 
Second, this study contributes measures to describe groups as belonging to a network. It is often assumed that it is one or the other - a network approach or a group approach - here, we adopt a hybrid method. We first define the group as the unit of analysis, and then apply a network approach to delineate boundaries, and follow the group's pattern of interactions over time. This method allows us to look at the group itself as an entity that is influenced by its immediate and larger set of relations looking at both its internal interactions, as well as its connections to other groups. Our approach contrasts from earlier work, which typically focuses on one or the other (e.g. McGloin, 2005; Papachristos, 2009). We focus on how both the internal and external network structure influences group-level outcomes.

Third, this study answers a call for the need to return to group-level analyses. After decades of stagnation, group-based studies have recently remerged as a new focus, with advances in network methods allowing researchers to study group dynamics using survey and official data. Despite this recent renaissance, much of the empirical literature on criminal groups is still characterized by the study of its individual members (see Maxson, 2015: 411; Pyrooz and Mitchell, 2015). This represents an important omission, as much theoretical and ethnographic research highlights the importance of the structural features of groups for understanding group-level processes; however, a lack of empirical data has precluded researchers from further pursuing this line of inquiry (Maxson, 2015). The approach here follows calls by SierraArevalo and Papachristos (2015) to employ network analysis to return studies to the group-level. The study's main contribution is to move beyond individual-level accounts of criminal groups, providing a longitudinal study of the processes influencing group dynamics.

\section{DATA AND METHODS}

Data on which this study is based come from a longitudinal dataset of gang-associated individuals identified in police records for the years 1993 to $2010(n=10,145)$ (Tremblay et al., 2016). Data collection relied on a self-referral process that retrieved offender and associate networks of gang members in police records through a twostage sampling design. The starting point was a convenience sample of 261 'seeds' identified by police as male Haitian street gang members. From these seeds, two rounds of sampling were conducted to retrieve the networks of their accomplices and associates. The first round of the sampling design, identified the contacts of the 'seeds', as recorded in police documents. Contacts of the Haitian street gang members were established based on whether they had been co-arrested, co-suspected, co- 
victims, co-present during a police stop, or police investigation files recorded an association. This first stage identified 2,992 first-degree contacts of the Haitian streetgang members, capturing all individuals who were connected to the seeds as well as the connections between the first-degree contacts. The second round reiterated this procedure, examining the criminal entourage of all Haitian males identified in the firstwave who had committed at least one police recorded offense during the sampling period (44\% of the first-degree contacts), adding an additional 6,998 associates to the network. $\underline{1}$ This created a final sample of 10,145 persons for the period 1993 to 2010 . The current study focuses only on the period 2001 to 2009 which has complete information on police stops and arrest records. This period captures 8,387 unique gang members and gang-associates. Of these, we focus on 79 percent $(n=6,604)$ of the unique individuals who had at least one recorded affiliation to another gangassociate, having been involved in a co-offense and/or observed in the company of another gang-associate during a police stop.

The focus on Haitian gang members also merits presenting a brief portrait of their background and growth in the Montreal area. The starting point of the study was prompted by fieldwork conducted by Tremblay (2011) on the founding members of the Haitian street gangs in Montreal. This research traced the emergence of the Haitian street gangs to the mid-1980s, a period during which a large wave of young, male immigrants moved to Montreal from Haiti. Many of the founding gang members consisted of first-generation immigrants who lived in close proximity, were failing to meet academic standards, and were faced with a lack of legitimate opportunities, consistent with previous accounts of the conditions under which gangs have emerged (e.g. Hagedorn, 1994; Short and Strodtbeck, 1965). Since then, these groups have evolved beyond first-generation immigrants, who are now found among the minority (Tremblay et al., 2016). Yet these same contextual circumstances, spatial proximity and lack of opportunities, has contributed to the continued evolution of Haitian street gangs into the late 2000s. Rather than consisting of a single homogenous entity, Haitian street gangs represent a number of distinct groups that are further embedded in the larger gang landscape of Montreal, which consists of other local groups, such as ethnic-based gangs and biker gangs (for an analysis of the genealogy of Haitian street gangs in Montreal, see Tremblay et al., 2016).

\section{DELINEATING CRIMINAL GROUP BOUNDARIES}

Because our data provide the networks of gang-associates, it affords the opportunity to delineate the boundaries of the criminal groups embedded in this structure. From 
these data criminal groups were identified through a three-step process. First, the data was segmented into three-year time windows (2001-2003; 2004-2006; 2007-2009). The decision to use three-year periods extended from the nature of the data source and empirical research on turnover in criminal groups. Our reliance on police data required the observation periods to be of a sufficient length so as to provide the opportunity for the 'full' scope of the group (and their relationships) to come to the attention of police. Longer time periods increased the likelihood that 'all' group members were first observed and then recorded in police files, something we return to in the discussion. Further, three-year periods also aligned with the literature on gang turnover, finding that most gang members only remain as such for a single year, while a subset persist for three or more years (Pyrooz, Sweeten, and Piquero, 2013), thus allowing us to proxy the natural turnover of criminal group membership.

Second, we created adjacency matrices for all gang-associates within each three-year period. For each adjacency matrix, the rows and columns consisted of the gangassociates, and the cell values of the matrix indicated whether any two of the gangassociates were adjacent. The adjacency matrices were binary, where a cell value of 0 indicated the absence of an association and a cell value of 1 indicated the presence of an association between any two gang-associates. The presence of an association was coded as 1 if any two gang-associates had been recorded in police files as having been arrested, suspected of a crime, or observed during a police stop together. Thus, associations represent co-offending relationships (i.e. joint participation in a criminal offense) and non-co-offending relationships (i.e. jointly observed together during a police stop). Information on associations between the individuals were obtained from 8,112 unique events (e.g. arrests; police-stops) recorded in police files. Of the 6,604 unique individuals in our sample, we found that 44 percent had been involved in at least one co-arrest, 82 percent had been involved in at least one police stop, and 27 percent had been observed in both police stop and co-arrest records. The networks derived from the adjacency matrices are presented in Figure 1. Each node indicates a unique individual, and each edge indicates a connection between individuals. Nodes are positioned using the Fruchterman-Reingold force-directed layout algorithm form the ggnetwork library (Briatte, 2016) in the statistical package R (R Core Team, 2018). From this visual representation a few patterns emerge. We find that many small groups are primarily on the periphery of the network, capturing cliques isolated from the rest of the gang-associates. In contrast, larger groups are mainly found in the core of the network, capturing the higher interconnectivity between the groups.

Insert Figure 1 about here 
Third, from the gang-association networks, we used the Louvain community detection procedure to locate distinct subgroups. The Louvain community detection method divides the network into an optimal number of subgroups (communities) based on individuals' patterns of interactions, seeking out local clusters of high interconnectivity. The optimal number of groups in the network are selected by the Louvain algorithm by maximizing the modularity coefficient through a multi-level method (Blondel et al., 2008). $\underline{2}$ The algorithm first detects sub-communities within the network based on members who have more dense connections with each another than with other members within the network, and then proceeds to build a network at the subgroup level, consisting of connections between the subgroups detected in the first step. By comparing the proportion of ties within communities to the proportion of ties between communities, the Louvain algorithm aims to maximize the modularity score, which is equal to zero when there are no within community ties and equal to one when all ties are within the community, with higher values indicating better fit (Newman and Girvan, 2004). The Louvain community detection method was applied to each adjacency matrix using the igraph library (Csardi and Nepusz, 2016) in the statistical package $R$ ( $R$ Core Team, 2018). This strategy led to the identification of 1,025 unique groups across all three periods. In line with our research design, we removed all groups that only had two members (i.e. dyads, $n=568$ ). Although these dyads are often included in studies of general co-offending (e.g. Carrington, 2016; Charette and Papachristos, 2017), their inclusion was not consistent with the current research design, consisting of dyadic relationships that lacked variation in our main variable of interest - the degree of their internal connectivity. In addition, we excluded all groups that formed in the third period (2007-2009) $(n=130)$ as they did not have the opportunity to survive more than one period.

In the study of criminal groups, community detection methods provide a means to delineate boundaries in cases where group membership (and interactions) may not be known. The novelty of community detection methods is that group boundaries are not established by researchers or participants, but rather through quantifiable measures based on observable characteristics of member behavior. Community detection methods have previously been used to identify deviant groups embedded in network data. For instance, Kreager, Rulison and Moody (2011) relied on friendship nominations, derived from school surveys to identify the presence of delinquent friendship groups, Lantz and Hutchison (2015) drew from co-offending data to delineate the boundaries of burglary groups, and Schaefer et al. (2017) used selfreported 'get-along with' nominations to reconstruct subgroups of inmates. 
Yet, while defining groups according to interactions is consistent with the network literature and recent research on delinquent groups, in many ways it departs from how groups in general, and gangs in particular have traditionally been defined. And thus, begs the question: to what extent our delineation of criminal groups aligns, or departs from how gangs have been defined in the past? Defining gangs has a long history in criminology scholarship, with longstanding disagreement characterizing the literature (for a review see Curry, 2015). The lack of consensus has typically centered on how to distinguish criminal groups from gangs, with the latter described as having an increased "groupness" (Warr, 2002; Papachristos, 2013: 49). Scholars have relied on a range of variables to discriminate between criminal groups and gangs, two of which are particularly relevant here: duration and self-identification.

First, gang definitions have often emphasized stability and durability (Klein and Maxson, 2006; Short and Strodtbeck, 1965) as key to distinguishing gangs from other criminal groups. $\underline{3}$ Whereas these studies use duration as the starting point to identify gangs, we use it as the end point. Our approach is more consistent with definitions that emphasize variation in duration across different gangs (e.g. also see Klein and Maxson, 2006). But also means that the persistent groups in our sample, those that survived extended periods, consist of groups that are more likely to be perceived as 'gangs', whereas those that did not survive, are more likely classified as 'criminal groups'. This means our sample likely captures what has been viewed as more ephemeral groups, groups that may be emerging into 'gangs', and established gangs.

Second, a considerable body of gang scholarship has emphasized individuals' selfidentification as central to distinguishing between gang and non-gang members. Selfidentification has been lauded as a reliable method to operationalize gang membership (see Esbensen et al. 2010), although it isn't without its limits (e.g. Melde, 2016). In this way, our operationalization of criminal groups departs from previous research in that we are unable to validate the full extent to which members self-identify as part of the specific group, or whether the groups in our sample capture symbolic in-group/outgroup boundaries seen as particularly important for the gang dynamics (Alleyne, Fernandes, and Pritchard, 2014; Hennigan and Spanovic, 2015).

Despite lacking information on members' self-identification, our approach is consistent with a body of work that emphasizes interactions are key to defining group membership (Homans, 1950: 363, also see Fleisher, 2006) and the structure of these interactions are central to explanations of group processes (Baron and Tinball, 1993; Densley, 2013; Homans, 1950; McCuish, Bouchard, and Corrado, 2015). In this way 
our approach captures groups of offenders who associate with one another in a set of relative dense interactions. Although these associations consist of both co-offending and non-co-offending relationships they represent the social environment in which these offenders, and would-be offenders are embedded and thus may more accurately represent the full group structure in which group processes and criminal norms are fostered. This is consistent with studies that emphasize the fluid boundaries of gangs and how interactions are central to group dynamics (Fleisher, 2006). Because policereported gang membership is known for only a minority of our sample $(n=583)$ and suggests our sample captures both 'gang' and 'non-gang members' $\underline{4}$, we refer to our sample as criminal groups and urge caution in conflating gang-association with gang membership. We elaborate on this and the use of police records to examine criminal groups further in the discussion, specifically in relation to the results.

\section{GROUP DURATION}

Our outcome variable, group duration, consists of a continuous measure of the number of periods a group was observed. Groups' duration ranged from a minimum of one to a maximum of three time periods. Groups were born if they had no members in the previous time period, and groups ended if they had no members in the following time period. Groups were defined as surviving if they had a stable set of members across two subsequent time periods. Thus, groups who survived could grow, bringing in new recruits, or could contract, with old members defecting. However, definitions of survival became more complicated when groups were defined as 'splitting' or 'merging'. In the former case, members belonging to the same group at time $t$ were spread across two or more groups in $t+1$. And conversely, in the latter case, members belonging to different groups at time $t$ belonged to the same group in time $t+1$. For these two scenarios, we took the group with the highest proportion of the persons from the previous time period (or following time period, for cases where groups merged) as having 'survived', whereas the other group(s) were identified as ending. $\underline{5}$ Specifically, this procedure was adapted from Palla, Barabási, and Vicsek (2007), and can be formally expressed as:

$$
C(A, B)=\frac{|A(t) \cap B(t+1)|}{|A(t) \cup B(t+1)|}
$$

Where $C$ refers to the community, A a person in Community A at time 1 and B a person in Community $\mathrm{B}$ at time $t+1$. We match groups by taking the sum of persons who are present in both groups across the two-time periods, divided by the total sum of persons 
who are present in either Community A at time $\mathrm{t}$ and/or Community B at time $t+1$. This created a ratio of the relative person overlap between communities across time periods. Designating the group with the higher proportion of persons across the previous time period as 'surviving', allowed us to follow the main portion of the group, rather than factions that break off (we assume the group with fewer members represents the 'faction').

Thus, our study applies a liberal definition of group duration, operationalized as a stable set of persons present in the same group across subsequent periods. Previous studies have operationalized criminal group duration as the time span between their first and last recorded criminal event (e.g. Miller, 2012). Here, our approach goes beyond the criminal event, applying an approach more consistent with Sarnecki (2001), defining a group's duration as the ability to maintain membership across consecutive time periods. However, this approach does not capture group's who experience a complete turnover in members yet still persist in its symbolic features. Our research complements that of Tremblay et al. (2016) who focused on continuity in the symbolic and expressive features of Haitian gangs. Ideally, we would have information on the qualitative and quantitative features of group persistence, which would allow us to capture both groups that persist with stable membership and those that persist in their symbolic features.

\section{COVARIATES}

To measure the predictors of group duration, four classes of covariates were operationalized from the police data: 1) controls (Haitian descent; proportion of members involuntarily removed; time period group was observed; and group size); 2) delinquency (proportion of crimes committed by offense category; and criminal productivity); 3) age-range; and 4) network variables (internal cohesion and alliances). Table 1 reports the summary statistics for the outcome and covariates. All covariates are continuous and dynamic, measured at the period the group was observed.

Insert Table 1 about here

All models include control variables for whether members were of Haitian descent and whether they were involuntarily removed from the group. Our measure of Haitian descent is a continuous variable of the proportion of all group members with a Haitian background. On average, 57 percent of all individuals in the group were of Haitian descent $(S D=.31)$. Given the network began from 261 seeds of police-recorded Haitian gang members, it is possible that these individuals may be overrepresented in 
the network, and therefore be more likely to be among the groups who persist, simply because of how the network was constructed. We also include a continuous measure of the proportion of members who were involuntarily removed from the group. Group members were defined as having been removed if they had been incarcerated, deported, or died in the current or subsequent observation period. Thus, denying them the opportunity to be observed the subsequent time period. Despite representing a network built out from law enforcement documents, on average only four percent of group members were incarcerated or removed from the network due to deportation or death within the subsequent period $(\mathrm{SD}=.10)$.

In addition, we also include a measure for the observation period in which the group was recorded. Police resources may have fluctuated across the three time periods, and thus some groups may have been more likely to be observed in some time periods than others. Relatedly, breaking down the observation periods into three-year windows means that some groups may be more likely to be observed in subsequent periods simply because they first appeared later in a preceding observation period. To control for this, we also include a measure of the average number of days since the beginning of the observation period that members of the group appeared in the police records. For instance, if members of a group observed in time period 1 (2001-2003) were recorded as being involved in three separate events, event 1: 35 days, event 2: 70 days, and event 3: 90 days after January 1, 2001, we included a measure capturing the fact that the group was observed on average 65 days since the beginning of the observation period. To facilitate interpretation of the coefficients, we convert our measure of days to months.

We also include a continuous measure of a group's size, logged to reduce skewness. The Montreal criminal groups on average had 18.32 members $(S D=32.00)$. The groups reported here are slightly smaller than other samples. For instance, Hughes (2013) relying on Short and Strodtbeck's (1965) ethnographic data reported an average group size of 49 members, ranging from 19 to 79 members. However, these differences are likely due to research design. Here, we include all co-offending groups (three or higher) whereas the gangs observed in Chicago consisted primarily of established criminal groups.

The models also include covariates on a group's delinquency. The police records contained information on all offenses each person had been arrested for or had been suspected of committing. From these offense data, five crime categories were created: violent (e.g. homicide; assaults; robbery; threats), market (e.g. drug/arms trafficking), 
drug use (e.g. drug possession - marijuana, crack, cocaine, and heroin - not for trafficking), property (e.g. larceny, fraud, auto theft, vandalism), and other offenses (e.g. driving infractions, public nuisance, violation of probation). There were also a few incidents recorded by police, but were not classified into any crime category. Rather than lose this information, we assume that the lack of classification means they were more likely to capture minor offenses and classify them as other. For each group, a continuous measure of the proportion of crimes committed by all members for each offense category was created. This measure was calculated by summing the total number of offenses committed by each person and dividing it by the total number of offenses.

The groups in our sample mainly committed offenses in the other category $(M=.41$; $S D=.29$ ), consisting primarily of minor offenses, such as violation of a probation condition, or a driving infraction, which may also explain the relatively low removal rates among our sample. The second most common crime for groups were violent offenses; on average 28 percent of all reported offenses by criminal groups were violent ( $S D=.27$ ). In comparison, criminal groups, on average, were involved in relatively few property $(M=.14 ; S D=.19)$, market $(M=.05 ; S D=.13)$, and drug use $(M=.01 ; S D=.05)$ offenses.

We also calculated a criminal productivity score for each group, a continuous measure of the average number of crimes committed by group members, logged to reduce skewness. Productivity was calculated by dividing the total number of offenses committed by group members by group size. On average, group members committed 2.56 offenses $(S D=3.36)$.

Age-graded structures are included as a continuous measure of the difference between the oldest and youngest members of the group. On average, the age range between the oldest and youngest member was 13.47 years $(S D=13.01)$. Our operationalization of age-graded structures draws from Klein and Maxson's (2006) typology of gang structures, who use the age range, as a method to distinguish between spontaneous gangs, and more traditional established gangs (also see Klein, 2002). We also use a measure of its dispersion, by taking the standard deviation of group members' year of birth. The age dispersion among our sample is an average of 4.11 years $(S D=3.09)$. While co-offending data has shown for a tendency to adopt homogeneous age structures (Warr, 1996; Carrington, 2016) our findings are similar with a body of research documenting a widening of age range across criminal groups (see Short, 2002; McGloin, 2005). However, on average, individuals in the sample were 23 years 
old when they were first observed in the dataset $(S D=7.92)$, and thus slightly older than some samples (e.g. Huff (1998) reported the median age of gang membership to be 14; Pyrooz (2014) using the NLSY97 showed gang membership peaked at age 15).

The main thrust of this study is testing whether a group's cohesion, and alliances to other groups influences group duration. Cohesion has been operationalized several different ways, often based on individuals' patterns of interactions. Previous studies have operationalized cohesion by using the number of contact hours or frequency with which gang members 'hang out' or 'get together' (Hennigan and Sloane, 2013; Jansyn, 1966). Here, we follow a body of research using network analysis methods that directly measure the interactions across members (Hughes, 2013; McGloin, 2005; for a review see Papachristos, 2013), to measure a group's cohesion (both internally and to other groups).

A group's internal cohesion was measured by its density, operationalized as the logged number of edges (in-ties) within the group. Density is typically calculated by taking the ratio of the total number of observed ties between group members to the total number of possible ties between members (Wasserman and Faust 1994). Scores of high density suggest a well-connected network and low scores imply low-connectivity between members. However, including ratios, such as density, directly in regression models along with measures involved in the calculation of those measures (e.g. group size) has been found to create modeling issues, as it assumes that the relation between the two components (i.e., in our case the number of ties, and number of possible ties) is proportionately constant. Previous studies have suggested that a more appropriate strategy is to parametrize the ratio by allowing both components to vary independently in the models (see Kronmal, 1993). Here, we measure density as simply the number of edges (i.e. ties) between group members, logged to reduce skewness. In addition, accounting for the fact that the number of edges a group will have will covary with group size, we also included an interaction between the number of members in a group and the number of edges. This allowed us to directly measure a group's density, while also controlling for issues of group size. We discuss this approach further in the results. In the descriptive statistics (Table 1) we report both the logged number of edges and a group's density.

On average, groups in our sample had an average density of .55 ( $S D=.34$ ), which demonstrated relatively high cohesiveness. In comparison, in Newark, McGloin (2005) found that all gangs in the sample had fewer than 10 percent of all possible connections between one another. We also calculated the average degree of criminal 
group members to effect comparisons with Hughes (2013). Our findings showed that measures of average degree were very slightly lower to those obtained by Hughes (2013), with an average degree of $1.80(S D=1.11)$ compared to $3.84(S D=3.11)$. However, when groups of less than five were removed results were comparable, with an average degree of $3.17(S D=1.77)$.

Groups' alliances, or degree to which they are embedded in the larger gang network is measured by the number of groups any one group was connected to. A connection between any two groups was coded as present if members from two respective groups had both been involved in at least one co-offense or both been observed together during a police stop. $\underline{6}$ In this way, our measure captures collaborative rather than conflict (victim-offender) relationships. $\underline{7}$ In other words, this variable measures the number of 'out-ties' any one group has, representing the counterpart to our measure of internal cohesion, which measures the number of 'in-ties' a group has. On average, groups in our sample had 1.34 out-ties (alliances) to other groups ( $S D=3.24$ ). The presence of alliances across groups is consistent with previous studies of Montreal gangs, which showed that on average groups had 1.2 positive relationships with other groups (Descormiers and Morselli, 2011), and Fleisher's (2006) study of girl gangs in Illinois which demonstrated that interpersonal ties cut across gang associations, even among groups who were engaged in disputes.

By including the direct effects of both the number of in-ties and out-ties in our models we are in essence measuring a group's E-I Index. The E-I index is a measure of the ratio of external-ties (i.e., alliances) to internal-ties (i.e., edges) (Krackhardt and Stern, 1988). It ranges from -1 to +1 , where -1 indicates the group is completely closed off and only has in-group ties and +1 indicating the group only forms external ties. Previous studies have emphasized that ratio of in-group to out-group ties is key for understanding process of recruitment and defection (McPherson, Popielarz, and Drobnic, 1992). We follow the same strategy here as we do for density, including both effects (i.e. edges and alliances) directly in the model, rather than the ratio (e.g. Kronmal, 1993). In addition, we allowed for the number of alliances to covary with a group's internal cohesion by also including an interaction term between the two measures. This allowed us to capture the direct effect of alliances, as well as the interaction between a group's external ties and in-ties. On average, groups in our sample had an E-I Index of -.98 ( $S D=.05)$, demonstrating that most groups were closed off, rarely forming alliances beyond their members. 
We report the summary statistics for a group's density and E-I index (ratio of internal to external ties) in Table1; however, models only include the interaction effect between group size and edges, and alliances and edges, respectively. Density [edges / ((size - 1 * size) / 2)] and the E-I index will still be used in its original form [(External-ties Internal-ties) / (External-ties + Internal-ties)] to present the results from the interaction effects.

\section{ANALYSIS}

To capture the effect of group-level predictors on group duration, a series of discrete event history models were estimated (Cox, 1972). This method provides a means to examine the longitudinal progression of the probability that an event will occur, while also accounting for predictors that may vary over time (Allison, 1984). The discretetime survival method is used, accounting for the fact that the outcome variable consisted of three-year intervals. All covariates were dynamic and thus did not violate the proportional hazards assumption. Given that a high number of individuals experienced the event at the same recorded time, the Efron method to handle ties was used. Efron approximation handles ties by using probability weights to adjust for risk (Efron, 1977) and is considered a more accurate method than Breslow approximation, which is more appropriate for cases that have a small number of failures relative to overall group size (Cleves et al., 2010).

An important challenge for estimating group duration concerned the unknown starting times for a subset of criminal groups. These groups were already active at time $t$ when the window period began, and thus we do not know the exact time period a group first emerged. This issue, referred to as left truncation, is treated in our models in two ways. First, we treat all groups observed in the first window period as if they had first emerged in time $t$ and not $t-x$. In addition, we control for this by including a measure of the period for when the group was first observed. We report discrete event history models using maximum likelihood estimation and standard errors clustered by group to account for non-independence of observations. Models were estimated using the survival library (Therneau, 2015) in the R statistical package (R Core Team, 2018).

\section{RESULTS}

\section{THE DURATION OF CRIMINAL GROUPS}

Table 1 shows that 327 criminal groups were identified within the gang-associate network. Similar to previous reports of criminal groups (e.g. Sarnecki, 2001; Warr, 
1996) they were highly transient, with most groups only surviving a single period ( $M=$ 1.49; $S D=.72)$. Figure 2 shows that the majority of groups (80\%) were only observed in one-time period. Of the groups that persisted, most survived two periods - with seven percent of all groups beginning in 2001-2003 ending in 2004-2006, and seven percent of all groups beginning in 2004-2006 ending in 2007-2009 (the last period of observation). Only a fraction of the criminal groups (5\%) were observed across all three time periods.

Insert Figure 2 about here

\section{PREDICTING CRIMINAL GROUP DURATION}

\section{Bivariate Results}

What leads a subset of criminal groups to persist over time? To answer this, we first present bivariate relationships between our explanatory variables and group duration. We then estimate discrete event history models to examine the full set of covariates and duration. Table 1 presents the bivariate correlations between our explanatory variables and outcome measure of group duration. These correlations indicate that group duration was positively and significantly associated with group size. By and large, the greater the number of individuals within a group, the greater the likelihood that at least one of the members will be observed in the subsequent period. The same holds true for groups that committed a higher proportion of market, drug use, and other offenses. Whereas the proportion of violent offenses had no impact on group duration. Groups with higher productivity scores also had a significantly higher likelihood of surviving longer periods, and consistent with Klein and Maxson's (2006) typology, criminal groups with a greater age range were more likely to survive longer periods. The strongest association with group duration were our network measures, alliances, and internal cohesion. The number of alliances a group had was positively and statistically significantly associated with group duration, even when accounting for internal connectivity (E-I Index). In contrast, groups with greater internal cohesion, as measured by their density were less likely to persist.

\section{Multivariate Results}

Table 2 presents a series of three discrete event history models. Model 1 provides the results of the baseline regression including only the control variables; Model 2 adds in our measure of age-graded structures and the direct effects for our network variables: alliances and internal cohesion (ln edges); and Model 3 introduces the interaction effects between our network variables. 
Model 1 shows that only a few of the control variables were significantly related to group survival. As shown in the first column, group size was positively associated with a group's duration $(H R=.58,95 \% C I=[.52-.64], p<.001)$, with larger groups more likely to be observed across subsequent time periods. Not surprisingly, the period during which a group was observed was negatively associated with their duration; groups that were observed earlier on were more likely to survive longer periods ( $H R=$ $1.21,95 \% C I=$ [1.03-1.42], $p=.022$ ). Similarly, groups with a higher proportion of members that had been forcibly removed (deported, killed or incarcerated) were less likely to survive $(H R=1.82,95 \% C I=[1.15-2.90], p=.011)$. None of our other controls, proportion of group members that are Haitian; and group criminality, were significantly related to group duration.

Insert Table 2 about here

Model 2 shows that, contrary to bivariate results, our measure of age range does not support the hypothesis that age-graded structures are positively associated with group duration. $\underline{8}$ Importantly, given the purpose of this paper, Model 2 shows that the direct effect of alliances, measured by the number of out-ties, is not significantly associated with group duration. However, cohesion, as measured by the number of edges (ln) is negative and significantly associated with group duration $(H R=1.67,95 \% C I=[1.05$ 2.65], $p=.030$ ). This suggests that more cohesive groups are less likely to survive over time. At this point it should be reiterated that the number of edges will be associated with group size, creating potential issues of multicollinearity. Multicollinearity can be highly problematic, creating power issues and undermining the significance of covariates. Previous network studies have dealt with these issues by using alternate measures of cohesion that are not as influenced by group size (e.g. Hughes, 2013: 809). However, in our case, despite low power, we find a significant effect for both the number of edges and group size, suggesting that for our specific context it does not create concerns (for a full discussion see O'Brien, 2007), although it does suggest that our point estimates may have wider confidence intervals. Further, by including edges as a direct effect in the model it allows us to include more precise measures of network connectivity, directly measuring the total number of in-ties within the group.

In Model 3 we explore this relationship between internal cohesion and group size by introducing an interaction effect between the two measures. In addition, we also include an interaction effect between our measure of alliances (external-ties) and internal cohesion (edges). The results show that both the interaction effect between 
group size and internal cohesion (ln edges $\times \operatorname{lnsize})(H R=.74,95 \% C I=[.56-.99], p=$ .040 ), and the interaction effect between the number of alliances and internal cohesion (ln alliances $\times \ln$ edges) $(H R=1.54,95 \% C I=[1.11-2.15], p=.010)$ are statistically significantly associated with group duration. Further, by including the interaction effects, the direct effect of internal cohesion (edges) loses its significance. This suggests that the relationship between our measures of cohesion and group duration are not driven by direct effects, but rather vary according to characteristics of the group, including its overall size and connectivity.

To interpret the interaction effects, we plot the hazard ratios for density for groups of varying size (Figure 3) and the hazard ratios for the E-I index for groups with varying number of edges (Figure 4). $\underline{9}$ Figure 3 shows that group size and cohesion work together to increase the likelihood of survival. Large groups have relatively stable hazards across all measures of density. However, smaller groups that adopt more cohesive structures are at a greater risk of ending. Figure 4 depicts similar differences between smaller and larger groups, according to the number of edges, showing that larger groups that have higher internal connectivity are more likely to fail when they form alliances beyond their group membership. In contrast, groups with lower internal connectivity are more likely to survive when they branch out beyond their immediate membership. This suggests that the association between cohesion and duration is conditioned by a group's relative size. Large groups need to turn on the inside to survive, while the survival of smaller groups depends on their ability to forge alliances outside.

\section{DISCUSSION}

The role of cohesion in influencing group survival has shaped early debates about group processes. On one side, scholars emphasized the costs of cohesion to group survival, limiting the ability of groups to recruit and replace defecting members. On the other, scholars pointed to the returns of cohesion to group survival, enhancing stability and solidarity among existing members. The current study provided evidence for a link between groups' cohesion and their survival. Yet, the influence of cohesion on groups' survival was not direct but moderated by the size of the organization. Whereas, large groups that adopted more closed structures were more likely to survive, small groups' survival depended on adopting less cohesive and more versatile structures. We interpret these results as reflecting two distinct, but related, mechanisms. Both have to do with the fundamentals of groups for survival and both 
are conditioned by a group's size: 1) a pool of potential recruits to draw from, and 2) incentives for recruits to select one particular group over alternatives.

First, group survival depends on effective channels of recruitment to replace ranks as they are depleted, an important factor in illicit contexts characterized by highly transient membership (e.g. Shaw and McKay, 1931; Warr, 2002). Social ties that span group boundaries shape a group's recruitment opportunities (Rochford, 1982; Snow, Zurcher, and Ekland-Olson, 1980). In this way, groups that establish links with other organizations are better equipped to access, screen, and recruit new members, and may enhance the opportunity for selection. These relationships provide greater access to a pool of potential recruits, providing gateways for the entrance of new members.

In contrast, groups with closed structures restrict ties internally and are less likely to form ties beyond their membership. For smaller groups that lack an established membership base, being closed off from the larger criminal milieu increases the risk of ending, when the removal of a few members depletes membership, lacking stores or access to new recruits. Previous research supports the link between alliances and group persistence. For instance, in a study of Chicago street gangs, Hughes (2013) outlined how some of the "gangs that began as play groups had developed age-graded subgroups and were beginning to form alliances as super-gangs and gang "nations" (Hagedorn, 2008; Short, 1974, 1976; Short and Moland, 1976, as quoted in Hughes, 2013: 803). Yet, the returns to recruitment for group survival may decrease when groups reach a certain size. A number of scholars, since the work of Reuter (1983) have theorized on the limits to criminal groups' growth (e.g. Bouchard and Ouellet, 2011; Kopp, 2004; Tremblay, Morselli, and Cusson, 1998). These scholars suggested that, beyond a certain threshold, new members may be counterproductive to group processes, with new recruits beginning to accrue greater costs than anticipated gains for the group. From this perspective, smaller groups are motivated to establish new relationships, whereas larger groups are motivated to maintain existing ones. This may also help explain differing findings across two prominent gang scholars. Hagedorn (1994) conducting fieldwork in Milwaukee suggested unstable, dynamic environments required groups to adopt flexible, less cohesive structures. Whereas SanchezJankowski (1991) conducting fieldwork across three US cities argued that "if gangs fail to build and maintain a cohesive structure they simply dissolve as organizations" (p. 91). Both studied gangs of different scales, with Hagedorn (1994) reporting an average of 16 members across the 18 different gangs studied, and Sanchez-Jankowski (1991) reporting on groups that ranged from 34 to 1,000 members across 37 gangs studied (group size was not reported by the two studies cited earlier; Klein and Crawford 
(1967) or Jansyn (1966)). Thus, different results may capture the presence of a threshold effect, where beyond a certain membership-level closed, cohesive structures becomes more important for group survival.

Second, group survival also depends on incentives for members to select one particular group over alternatives. A group's size is linked to their social environment, including the number of direct benefits they can offer to their members. Larger groups who have established membership may be better positioned to offer returns to members on a scale not possible for smaller groups. Large groups provide a larger pool of potential co-offenders, and are better able to offer social capital for members embedded in these structures. In contrast, small groups need to branch out to provide access to the same criminal opportunities offered by larger ones. Consistent with previous research, which shows that brokerage enhances access to lucrative opportunities (e.g. Burt, 1992; Morselli and Tremblay, 2004), smaller groups that bridge out to other gangs may be more likely to access a wider and more diverse range of opportunities, to give them a competitive edge on par with larger organizations. From this perspective, the same dyadic structures that create channels for recruitment also serve as channels for criminal opportunities, and ultimately incentives to fuel continued engagement while attracting new members. As the size and structure of groups shift, so do the necessary opportunities and constraints afforded by these organizations.

\section{THE GROUP VOLATILITY PARADOX}

Our results help link together various lines of inquiry associated with co-offending, and the boundaries of criminal groups. More specifically, our results provide a more concrete illustration of why criminal groups can be both small and ephemeral, and yet, represent such important entities for many offenders who associate with them. The apparent contradiction between the ever-changing, yet, ubiquitous criminal groupings is in fact very much driven by an over-emphasis on changes in specific co-offending dyads for detected crimes, rather than a search for a more stable core of offenders who interact together frequently - though not exclusively. Some of this emphasis is telling of a reality that was confirmed in our analyses, namely that most groups fail to persist, even when looser criteria for what constitute a group are used. Yet, insisting on the volatility of co-offending dyads may deny scholars the chance to consider the sociological importance of groups in our understanding of offending pathways and the regeneration of criminal opportunities. These persistent groups defy the many odds that are against them, from the difficulty in being observed in police data over 
different time periods - data which capture only a fraction of all socio-criminal interactions, to the fact that, individually, few offenders persist in criminal careers in the first place. These persistent groups are of sociological importance also for the influence they have on others who wish to emulate them, or to join them.

Our results also suggest that an over-emphasis on the apparent volatility of cooffending may hide an important mechanism for group survival, namely that small groups are best served by relying on strategic connections to apparent "outsiders". The turnover in membership on the periphery may in fact hide a relatively stable core of group members who strive for the generation, and re-generation of criminal opportunities; for themselves, and for the co-offenders who come in, and out of the core. Yet, without granular data on the returns per crime, much of this interpretation is merely conjectures. Our results illustrate an important gap in the literature on the creation, availability, and (especially) the relative attractiveness of criminal opportunities for offenders.

\section{LIMITATIONS}

The data obtained from police records allowed us to apply dynamic network models to test whether groups' internal cohesion, as well as embeddedness within the wider structure was associated with survival. Although research highlights the utility of police records for mapping co-offending networks, providing insight into criminal groups on a scale typically inaccessible to researchers (e.g. Charette and Papachristos, 2017; McCuish, Bouchard, and Corrado, 2015; McGloin and Piquero, 2010; Papachristos and Wildeman, 2014; Papachristos, Wildeman, and Roberto, 2015; Papachristos et al., 2015) it isn't without its limitations. In addition to the usual biases inherent in using official data (e.g. the police decision making process, see Black, 1970), police records likely underestimate the: 1) scope of criminal groups; and 2) connections between individuals within and across groups. Importantly, these missing data issues are also not necessarily randomly distributed across criminal groups. Police records may be more likely to represent persons deemed 'priorities' and for which there are sufficient resources. Our starting point of 261 seeds may help mitigate this limitation. All seeds were identified by police as gang members. Therefore, they may be more likely to have undergone police surveillance and capture more full representations of the criminal groups they associated with. However, the absence of a tie between two individuals does not mean they were not connected, only that it was not observed in police records. 
The limits of using a two-stage sampling strategy as the starting point to create the groups in our sample should also be noted. Ideally, we would have access to the full set of gang members and their associates as detailed in police records, and then delineate criminal group boundaries (e.g. see Papachristos, Wildeman and Roberto, 2015). By starting with the ego-networks of 261 'seeds' and then collecting their contacts twosteps away, we may miss other criminal groups that were not part of these seeds' direct or indirect networks, and potentially the full group structure to which the seeds belonged. To verify this possibility, we also ran the Louvain community detection procedure on the 'whole population' - the entire set of individuals and interactions recorded in police arrest and stop data over this same time period - and compared them to our dataset. The results showed that the communities detected from the full sample of municipal police records are similar to those obtained through our approach. Having the classification from our 'street gang' subset improves the probability of assigning the right clusters from the whole sample by 79 to $85 \%$. (Uncertainty Coefficient (UC): T1: $\mathrm{UC}=0.84$; $\mathrm{T} 2$ : $\mathrm{UC}=0.85$; $\mathrm{T} 3$ : $\mathrm{UC}=0.79$ ). Thus, in absence to having access to all members within the full dataset for the discrete event history models, our two-stage sampling approach highlights some consistency with more sociocentric approaches.

A related limitation concerns the sampling strategy and police-recorded 'gang' label. While our sampling strategy used police recorded gang members as the seed of the sample, not all individuals that associated with these gang members were known to police as members themselves. We have information on police-reported gang membership for 28 percent of the sample $(n=1,839)$. Of these individuals, only a third ( $n=583$ ) were known gang members with the remaining described as non-gang members $(n=1,256)$. Further, non-gang members were more likely to be found twosteps away from the seeds than individuals one-step. $\underline{10}$ Thus, individuals closer to the seed are more likely to be reported as gang members by the police. This may be related to differences in how police record gang members (ie their affiliates). Although we lack information on self-reported gang membership, all individuals in our sample committed at least one criminal offense from the period 1993 to 2010.

Much research on criminal networks using police sources rely on arrest records to map individual connections. Here, we have both arrest records (i.e. co-offending) and police stops, which allows us to recreate the criminal-social ties among individuals. This approach helps us overcome underreporting in official sources and is consistent with scholars that emphasize the importance of both criminal and non-criminal ties in groups (e.g. see Curry, 2015), but isn't without its limits. Police stops aren't same as co- 
offending and neither provide us with detailed information about the nature of the relationship. Despite lacking data on the precise nature of the interaction, we believe that data derived from police-stops and co-offenses provide a means to measure the structure of criminal groups and is consistent with scholars that emphasize the proximity of interactions as key to distinguishing group members (e.g. Densley, 2013: 137). Consistent with Pyrooz, Decker and Webb (2014), we encourage others to examine further the nature of the relationships.

These limits are not unique to the use of police records but is also symptomatic of larger sets of problems that confront the study of criminal groups, including the identification and observation of members and their interactions over time (e.g. Klein, 2005; Warr, 1996: 19). Although these limits confront many studies assessing the network dynamics of criminal groups, it carries important implications for the current study, as our measure of group survival depends on members being observed in official sources across multiple periods. On one hand, the length of the time intervals helps mitigate this, with a three-year window used for police to observe and record gangaffiliated members. However, it should also be recognized that groups that were classified as 'not surviving' may purely have evolved into organizations that are better able at evading police contact or fell off the police radar. Meehan's (2000) report on police gang statistics, shows how police record keeping may be influenced by ongoing politics related to the gang problem (also see Brayne, 2017). While not all delinquent acts, actors, or relations may be captured by police records, we argue that the data source provides a good starting point for understanding group dynamics, providing information on members and their interactions over time, two criteria necessary to understand dynamic group processes that might not be readily available through alternative data collection strategies. But their limitations should be kept in mind.

An additional limitation is that the covariates specific to this study (age-graded structures, alliances, internal cohesion) are not a complete list; rather this study highlights specific variables in an effort to provide a useful framework to systematically look at parameters of group trajectories. And thus, misses some of the unique contexts of gang formation identified by previous researchers. As outlined by Decker, van Gemert, and Pyrooz (2009) factors instrumental to gang formation, such as threat and contagion (Decker, 1996), defensive reaction formation (Alonso, 2004), aleatory risk (Strodtbeck and Short, 1964), and defensive localism (Adamson, 2000) are not included in this study. Relatedly, our data emphasizes collaborative relationships, as compared to retaliatory ones. This may be due to the unique context of the Montreal gangs, which have relatively low rates of police recorded conflict 
between groups as compared to other samples, such as gangs in Chicago. The relatively high rates of minor offenses and low rates of violence between groups, may have important implications on group processes. Future studies should explore the link between cohesion and violence in relation to survival in other samples of criminal groups.

\section{CONCLUSION}

This study's results suggest that network structures differentially impact the persistence of criminal groups. Groups at different stages in their evolution required different network structures to survive: groups that were in their early stages of formation adopted more versatile structures, enhancing their access to criminal opportunities, whereas more established groups adopted closed structures to maintain their existing positions. These findings highlight that the network properties associated with survival for more established groups are at odds for those groups that are just emerging and looking to establish themselves. Groups must adapt to their current circumstances and adopt network structures that match their existing conditions, aligning with early theoretical contentions of group structure: versatility brings access to new opportunities and growth, whereas closure enhances the stability of established groups.

\section{REFERENCES}

Adamson, Christopher. 2000. Defensive localism in white and black: A comparative history of European-American and African-American youth gangs. Ethnic and Racial Studies 23: 272-98.

Alleyne, Emma, Isabel Fernandes, and Elizabeth Pritchard. 2014. Denying humanness to victims: How gang members justify violent behavior. Group Processes \& Intergroup Relations 17:750-762.

Allison, Paul D. 1984. Event History Analysis: Regression for Longitudinal Event Data. Newbury Park, CA: Sage Publications.

Alonso, Alejandro A. 2004. Racialized identities and the formation of black gangs in Los Angeles. Urban Geography 25:658-74.

Andresen, Martin A., and Marcus Felson. 2010. The impact of co-offending. British Journal of Criminology, 50:66-81. 
Baron, Stephen W., and David B. Tindall. 1993. Network structure and delinquent attitudes within a juvenile gang. Social Networks 15:255-273.

Black, Donald J. 1970. The production of crime rates. American Sociological Review 35:733-48.

Blondel, Vincent D. Jean-Loup Guillaume, Renaud Lambiotte, and Etienne Lefebvre. 2008. Fast unfolding of communities in large networks. Journal of Statistical Mechanics: Theory and Experiment 10:P10008.

Bouchard, Martin, and Carlo Morselli. 2014. Opportunity structures of organized crime. In Handbook of Organized Crime, ed. Letizia Paoli. Oxford: Oxford University Press.

Bouchard, Martin and Frédéric Ouellet. 2011. Is small beautiful? The link between risks and size in illegal drug markets. Global Crime 12:70-86.

Brayne, Sarah. 2017. Big data surveillance: The case of policing. American Sociological Review 82(5) 977-1008.

Briatte, Francois. 2016. Ggnetwork: Geometries to Plot Networks with 'ggplot2'. R package version 0.5 .1 .

Bright, David A. 2015. Disrupting and dismantling dark networks: Lessons from social network analysis and law enforcement simulations. In Illuminating Dark Networks: The Study of Clandestine Groups and Organizations, ed. Luke M. Gerdes. New York: Cambridge University Press.

Burt, Ronald S. 1992. Structural Holes. Cambridge, Mass.: Harvard University Press. Burt, Ronald S. 2004. Structural holes and good ideas. American Journal of Sociology 110:349-99.

Burt, Ronald S. 2005. Brokerage and Closure: An Introduction to Social Capital. Oxford: Oxford University Press.

Calderoni, Francesco, Domenico Brunetto, and Carlo Piccardi. 2017. Communities in criminal networks: A case study. Social Networks 48:116-25.

Carrington, Peter J. 2016. Gender and age segregation and stratification in criminal collaborations. Journal of Quantitative Criminology 32:613-49. 
Charette, Yanick, and Andrew V. Papachristos. 2017. The network dynamics of cooffending careers. Social Networks 51:3-13.

Clauset, Aaron, Mark E. J. Newman, and Cristopher Moore. 2004. Finding community structure in very large networks. Physical Review 70: 066111-1-6.

Cleves, Mario, Roberto G. Gutierrez, William Gould, and Yulia V. Marchenko. 2010. An Introduction to Survival Analysis using Stata, 3rd ed. College Station, TX: Stata Press.

Coleman, James S. 1988. Social capital in the creation of human capital. American Journal of Sociology 94:S95-S120.

Coleman, James S. 1990. Foundations of Social Theory. Boston, MA: Harvard University Press.

Collins, Randall. 1988. Theoretical Sociology. New York: Harcourt Brace Jovanovich.

Coser, Lewis. 1974. Greedy Institutions: Patterns of Undivided Commitment. New York: Free Press.

Cox, David R. 1972. Regression models and life-tables. Journal of the Royal Statistical Society, Series B (Methodological) 34: 187-220.

Csardi G, and Tamas Nepusz. 2006. The igraph software package for complex network research, InterJournal, Complex Systems 1695.

Cunningham, Daniel, Sean F. Everton, and Philip J. Murphy. 2016. Understanding Dark Networks: A Strategic Framework for the Use of Social Network Analysis. Lanham, MD: Rowman and Littlefield.

Curry, G. David. 2015. The logic of defining gangs revisited. In The handbook of gangs, eds Scott H. Decker, and David C. Pyrooz. Malden, MA: John Wiley \& Sons, Inc.

Curry, G. David, Scott H. Decker, and Arlen Egley Jr. 2012. Gang involvement and delinquency in a middle school population. Justice Quarterly 19:275-92.

Curry, G. David, and Irving A. Spergel. 1988. Gang homicide, delinquency, and community. Criminology 26:381-406.

Decker, Scott H. 1996. Collective and normative features of gang violence. Justice Quarterly 13: 243-64. 
Decker, Scott H., and Barrik van Winkle. 1996. Life in the gang: Family, friends, and violence. Cambridge, UK: Cambridge University Press.

Decker, Scott. H., and G. David Curry. 2002. Gangs, gang homicides, and gang loyalty: Organized crimes or disorganized criminals. Journal of Criminal Justice 30:343-52.

Decker, Scott H., Frank van Gemert, and David C. Pyrooz. 2009. Gangs, migration, and crime: The changing landscape in Europe and the USA. International Migration and Integration 10:393-408.

Densley, James A. 2012. Street gang recruitment: Signaling, screening, and selection. Social Problems 59:301-321.

Densley, James A. 2013. How Gangs Work. New York, NY: Palgrave Macmillan.

Densley, James A. 2015. Joining the gang: A process of supply and demand. In The handbook of gangs, eds Scott H. Decker, and David C. Pyrooz. Malden, MA: John Wiley \& Sons, Inc.

Descormiers, Karine, and Carlo Morselli. 2011. Alliances, conflicts, and contradictions in Montreal's street gang landscape. International Criminal Justice Review 21:297-314.

Efron, Bradley. 1977. The efficiency of Cox's likelihood function for censored data. Journal of the American Statistical Association 72:557-65.

Esbensen, Finn-Aage, Thomas Winfree, Jr., Ni He Terrance J. Taylor. 2001. Youth gangs and definitional issues: When is a gang a gang, and why does it matter? Crime and Delinquency 47:1015-130.

Fleisher, Mark S. 1998. Dead End Kids: Gang Girls and the Boys They Know. Madison: University of Wisconsin Press.

Fleisher, Mark S. 2005. Fieldwork research and social network analysis: Different methods creating complementary perspectives. Journal of Contemporary Criminal Justice 21:1-15.

Fleisher, Mark S. 2006. Youth gang social dynamics and social network analysis: Applying degree centrality measure to assess the nature of gang boundaries. In Studying youth gangs, eds. James F. Short and Lorine A. Hughes. Lanham, MI: Altamira Press 
Girvan, Michelle, and Mark E. J. Newman. 2002. Community structure in social and biological networks. Proceedings of the National Academy of Sciences 99:7821-26.

Granovetter, Mark S. 1973. The strength of weak ties. American Journal of Sociology 78:1360-1380.

Hagedorn, John M. 1994. Neighborhoods, markets, and gang drug organization. Journal of Research in Crime and Delinquency 31: 264-94.

Hagedorn, John M. 2008. A World of Gangs: Armed Young Men and Gangsta Culture. Minneapolis: University of Minnesota Press.

Hennigan, Karen M., and David Sloane. 2013. Improving civil gang injunctions: How implementation can affect gang dynamics, crime, and violence. Criminology \& Public Policy 12:7-41.

Hennigan, Karen M., and Marija Spanovic. 2012. Gang dynamics through the lens of social identity theory. In Youth gangs in international perspective: Results from the Eurogang program of research, eds. Finn-Aage Esbensen, and Cheryl L. Maxson. New York: Springer.

Homans, George C. 1950. The Human Group. New York: Harcourt, Brace and Company. Horowitz, Ruth. 1983. Honor and the American Dream: Culture and Identity in a Chicano Community. New Jersey: Rutgers.

Huff, C. Ronald. 1998. Comparing the criminal behavior of youth gangs and at-risk youths: Research in brief. Washington, DC: Department of Justice.

Hughes, Lorine A. 2013. Group cohesiveness, gang membership prestige, and delinquency and violence in Chicago, 1959-1962. Criminology 51: 795-832.

Jansyn, Leon R. Jr. 1966. Solidarity and delinquency in a street corner group. American Sociological Review 31:600-14.

Kanter, Rosabeth Moss. 1972. Commitment and Community: Communes and Utopias in Sociological Perspective. Cambridge, MA: Harvard University Press.

Klein, Malcolm W. 1971. Street Gangs and Street Workers. Prentice-Hall.

Klein, Malcom W. 2002. Street gangs: A cross-national perspective. In Gangs in America III, ed., Ronald C. Huff. London, U.K.: Sage Publications. 
Klein, Malcolm W. 2005. The value of comparisons in street gang research. Journal of Contemporary Criminal Justice 21:135-152.

Klein, Malcolm W., and Lois Y. Crawford. 1967. Groups, gangs, and cohesiveness. Journal of Research in Crime and Delinquency 4:63-75.

Klein, Malcolm W., and Cheryl L. Maxson. 2006. Street Gang Patterns and Policies. New York: Oxford University Press.

Klein, Malcolm W., Frank M. Weerman, and Terence P. Thornberry. 2006. Street gang violence in Europe. European Journal of Criminology 3:413-437.

Kopp, Pierre. 2004. Political Economy of Illegal Drugs. New York, NY: Routledge.

Krackhardt, David, and Robert N. Stern. 1988. Informal networks and organizational crises: An experimental simulation. Social Psychology Quarterly 51:123-40.

Kreager, Derek A., Kelly Rulison, and James Moody. 2011. Delinquency and the structure of adolescent peer groups. Criminology 49:95-127.

Kronmal, Richard A. 1993. Spurious correlation and the fallacy of the ratio standard revisited. Journal of the Royal Statistical Society 156:379-392.

Lantz, Brendan, and Robert Hutchison. 2015. Co-offender ties and the criminal career: The relationship between co-offender group structure and the individual offender. Journal of Research in Crime and Delinquency 52:658-690.

Lucore, Patricia. 1975. Cohesiveness. In the gang. In Gang Delinquency, eds. Desmond S. Cartwright, Barbara Tomson, and Hershey Schwartz. Monterey, CA: Brooks/Cole.

Malm, Aili, Gisela Bichler, and Rebecca Nash. 2011. Co-offending between criminal enterprise groups. Global Crime 12:112-28.

Maxson, Cheryl L. 2015. The legacy of Malcolm W. Klein. In The handbook of gangs, eds Scott H. Decker, and David C. Pyrooz. Malden, MA: John Wiley \& Sons, Inc.

McCarthy, Bill, John Hagan, and Lawrence E. Cohen. 1998. Uncertainty, cooperation, and crime: Understanding the decision to co-offend. Social Forces 77:155-176.

McCuish, Evan, Martin Bouchard, and Raymond Corrado. 2015. Searching for suitable homicide co-offenders among gang members. Journal of Contemporary Criminal Justice 31: 319-336. 
McGloin, Jean Marie. 2005. Policy and intervention considerations of a network analysis of street gangs. Criminology \& Public Policy 4:607-35.

McGloin, Jean Marie, and Alex Piquero. 2010. On the relationship between cooffending network redundancy and offending versatility. Journal of Research in Crime and Delinquency 47:63-90.

McPherson, J. Miller, Pamela A. Popielarz, and Sonja Drobnic. 1992. Social networks and organizational dynamics. American Sociological Review 57:153-70.

Meehan, Albert J. 2000. The organizational career of gang statistics: The politics of policing gangs. The Sociological Quarterly 41:337-70.

Melde, Chris. 2016. Gangs and gang crime. In The handbook of measurement issues in criminology and criminal justice, ed Beth M. Huebner, and Timothy S. Bynum. West Sussex, UK: John Wiley \& Sons.

Melde, Chris, and Finn-Aage Esbensen. 2014. The relative impact of gang status transitions: Identifying the mechanisms of change in delinquency. Journal of Research in Crime and Delinquency 51:349-376.

Miller, Erin. 2012. Patterns of onset and decline among terrorist organizations. Journal of Quantitative Criminology 28:77-101.

Miller, Walter B. 1974. American youth gangs: Past and present. In Current Perspectives on Criminal Behavior, ed. Abraham S. Blumberg. New York, NY: Knop.

Morselli, Carlo, and Pierre Tremblay. 2004. Criminal achievement, offender networks and the benefits of low self-control. Criminology 42:773-804.

Newman, Mark E., and Michelle Girvan. 2004. Finding and evaluating community structure in networks. Physical Review E, 69:026113.

Nguyen, Holly and Jean Marie McGloin. 2013. Does economic adversity breed criminal cooperation? Considering the motivation behind group crime. Criminology 51: 833-70.

Palla, Gergely, Albert-Lázló Barabási, and Tamás Vicsek. 2007. Quantifying social group evolution. Nature 446:664-67.

Papachristos, Andrew V. 2009. Murder by structure: Dominance relations and the social structure of gang homicide. American Journal of Sociology 115:74-128. 
Papachristos, Andrew V. 2013. The importance of cohesion for gang research, policy, and practice. Criminology \& Public Policy 12:49-58.

Papachristos, Andrew V, Anthony A. Braga, Eric Piza, and Leigh S. Grossman. 2015. The company you keep? The spillover effects of gang membership on individual gunshot victimization in a co-offending network. Criminology 53:624-49.

Papachristos, Andrew V., and Christopher Wildeman. 2014. Network exposure and homicide victimization in an African American community. American Journal of Public Health 104:143-50.

Papachristos, Andrew V., and Christopher Wildeman, and Elizabeth Roberto. 2015. Tragic, but not random: The social contagion of nonfatal gunshot injuries. Social Science \& Medicine 125:139-150.

Perkins, Useni Eugen. 1987. Explosion of Chicago's Black Street Gangs: 1900 to the Present. Chicago: Third World Press.

Pyrooz, David C. 2014. "From your first cigarette to your last dyin' day": The patterning of gang membership in the life-course. Journal of Quantitative Criminology 30:349-372.

Pyrooz, David C., and Meghan M. Mitchell. 2015. Little gang research, big gang research. In The handbook of gangs, eds Scott H. Decker, and David C. Pyrooz. Malden, MA: John Wiley \& Sons, Inc.

Pyrooz, David C., Scott H. Decker, and Vincent J. Webb. 2014. The ties that bind: Desistance from gangs. Crime \& Delinquency 60:491-516.

Pyrooz, David C., and Gary Sweeten. 2015. Gang membership between ages 5 and 17 years in the United States. Journal of Adolescent Health 56:414-419.

Pyrooz, David C., Gary Sweeten, and Alex R. Piquero. 2013. Continuity and change in gang membership and gang embeddedness. Journal of Research in Crime and Delinquency 50:239-71.

Pyrooz, David C., Jillian J. Turanovic, Scott H. Decker, and Jun Wu. 2016. Taking stock of the relationship between gang membership and offending. Criminal Justice and Behavior 43:365-397. 
R Core Team. 2018. R: A Language and Environment for Statistical Computing.

Austria: R Foundation for Statistical Computing. http://www.R-project.orgL.

Reuter, Peter. 1983. Disorganized Crime: The Economics of the Visible Hand. Cambridge, MA: MIT Press.

Rochford, E. Burke. 1982. Recruitment strategies, ideology, and organization in the Hare Krishna movement. Social Problems 29:399-410.

Sanchez-Jankowski, Martin. 1991. Islands in the Street: Gangs and American Urban Society. Los Angeles, CA: University of California Press.

Sarnecki, Jerzy. 2001. Delinquent Networks: Youth Co-offending in Stockholm. Cambridge, U.K.: Cambridge University Press.

Schaefer, David. R., Martin Bouchard, Jacob T. N. Young, and Derek A. Kreager. 2017. Friends in locked places: An investigation of prison inmate network structure. Social Networks 51: 88-103.

Shaw, Clifford, and Henry H. McKay. 1931. Social factors in juvenile delinquency. In Report on the Cause of Crime, vol. 2, National Commission on Law Observance and Enforcement. Washington, DC: Government Printing Office.

Shi, Yongren, Fedor A. Dokshin, Michael Genkin, and Matthew E. Brashears. 2017. A member saved is a member earned? The recruitment-retention trade-off and organizational strategies for membership growth. American Sociological Review 82:407-34.

Short, James. F. Jr. 1974. Youth, gangs, and society: Micro- and macro-sociological processes. The Sociological Quarterly 15:3-19.

Short, James. F. Jr. 1976. Gangs, politics, and the social order. In Delinquency, Crime, and Society, ed. James F. Short Jr. Chicago, IL: University of Chicago Press.

Short, James F. Jr. 2002. Foreword: what is past is prelude: Gangs in America and elsewhere. In Gangs in America III, ed. Ronald C. Huff. London, U.K.: Sage Publications.

Short, James F., Jr., and John Moland, Jr. 1976. Politics and youth gangs: A follow-up study. Sociological Quarterly 17: 162-179. 
Short, James F., and Fred L. Strodtbeck. 1965. Group Process and Gang Delinquency. Chicago, IL: University of Chicago Press.

Sierra-Arevalo, Michael, and Andrew V. Papachristos. 2015. Social network analysis and gangs. In The handbook of gangs, eds Scott H. Decker, and David C. Pyrooz. Malden, MA: John Wiley \& Sons, Inc.

Snow, David, Louis A. Zurcher, and Sheldon Ekland-Olson. 1980. Social networks and social movements: A micro structural approach to differential recruitment. American Sociological Review 45:787-801.

Spergel, Irving A. 1966. Street Gang Work: Theory and Practice. Reading, MA: AddisonWesley.

Spergel, Irving A. 1995. The Youth Gang Problem: A Community Approach. Oxford: Oxford University Press.

Strodtbeck, Fred L., and James F. Short. 1964. Aleatory risks versus short-run hedonism in explanation of gang action. Social Problems 12:127-40.

Tenti, Valentina, and Carlo Morselli. 2014. Group co-offending networks in Italy's illegal drug trade. Crime, Law \& Social Change 62:21-44.

Therneau, Terry M. 2015. A Package for Survival Analysis in S, version 2.38. https://CRAN.R-project.org/package=survival

Thrasher, Frederic M. 1927. The Gang: A Study of 1,313 Gangs in Chicago. Chicago, IL: University of Chicago Press.

Tremblay, Pierre. 2011. Beauvoir Jean, Le récit du vétéran. Liber : Montréal.

Tremblay, Pierre, Carlo Morselli, and Maurice Cusson. 1998. Market offenses and limits to growth. Crime, Law and Social Change 29 :311-330.

Tremblay, Pierre, Matthew Charest, Yanick, Charette, and Marc Tremblay-Faulkner. 2016. Le délinquant affilié: La sous-culture des gangs de rue haïtiens de Montréal. Montréal: Liber.

Vargas, Robert. 2014. Criminal group embeddedness and the adverse effects of arresting a gang's leader: A comparative case study. Criminology 52:143-68. 
Vigil, James D. 1988. Barrio Gangs: Street Life and Identity in Southern California. Austin: University of Texas Press.

Vigil, James D. 2002. A Rainbow of Gangs: Street Cultures in the Mega-city. Austin: University of Texas Press.

Warr, Mark. 1996. Organization and instigation in delinquent groups. Criminology 34:11-37.

Warr, Mark. 2002. Companions in Crime: The Social Aspects of Criminal Conduct. New York: Cambridge University Press.

Weisel, Deborah L., Scott Decker, and Timothy S. Bynum. 1997. Gangs and Organized Crime Groups: Connections and Similarities Final Report. Washington, DC: National Institute of Justice.

\section{Figure 1. Networks of Gang-affiliates (node-level) ${ }^{a, b}$}

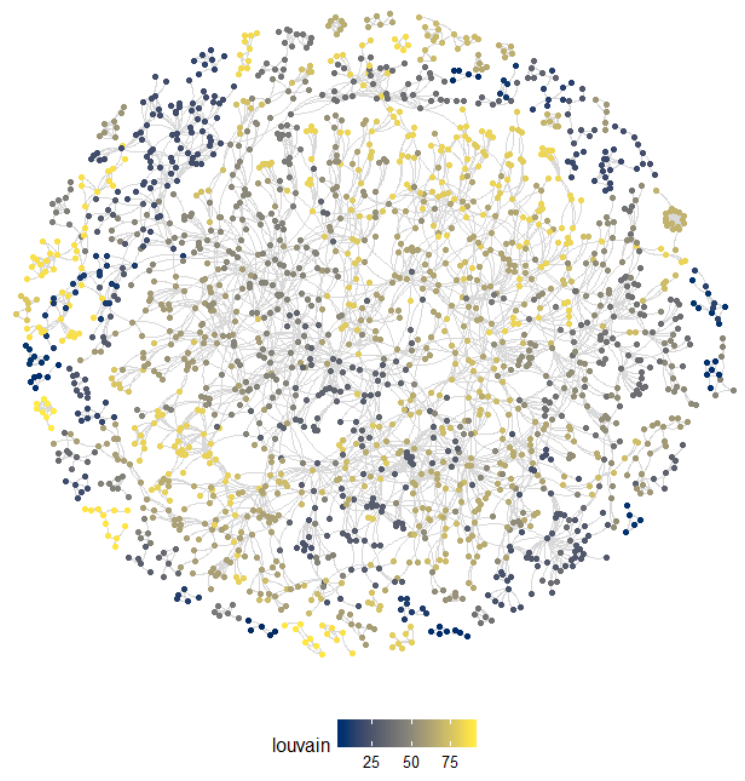



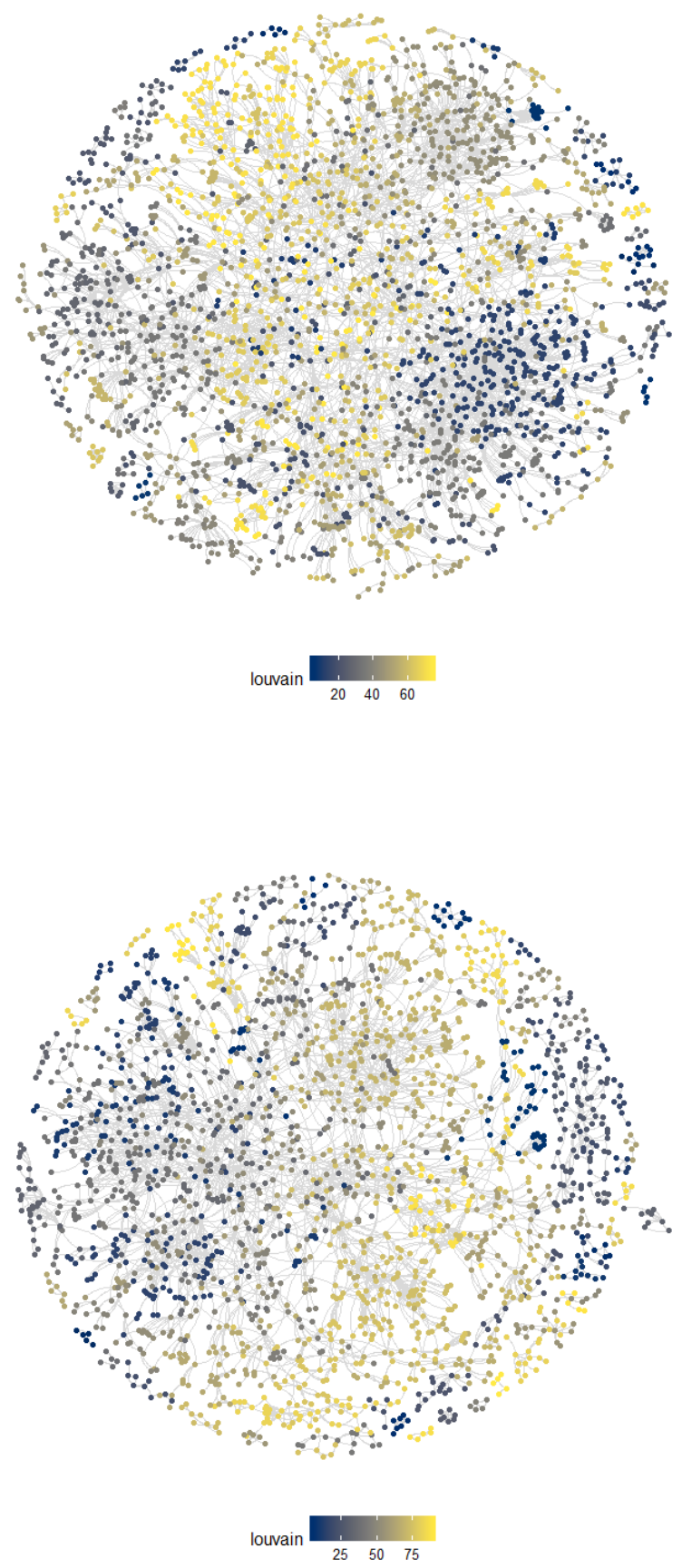

\begin{tabular}{|l|l|l|l|}
\hline Period & 2001-2003 & 2004-2006 & 2007-2009 \\
\hline N Nodes & 2340 & 2677 & 3137 \\
\hline N Groups & 172 & 196 & $172^{\mathrm{C}}$ \\
\hline Density & .002 & .002 & .001 \\
\hline
\end{tabular}


a Nodes are positioned using the Fruchterman-Reingold algorithm. Groups with fewer than five members not shown.

$\mathrm{b}$ Colors are used to help delineate the group boundaries identified by the Louvain community detection algorithm. They are intended to help denote different clusters of individuals, but not meant for exact precision given the scale.

${ }^{\mathrm{c}}$ This includes the 130 groups that were excluded from the final sample.

\section{Figure 2. Group Survivala}

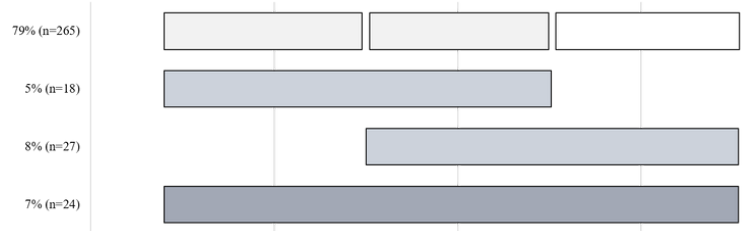

${ }^{a}$ Groups that emerged in final observation period $(n=130)$ are not included in the percentages.

\section{Figure 3. Interaction Effect Between Groups' Internal Cohesion and Size on Group Persistence ${ }^{a}$}

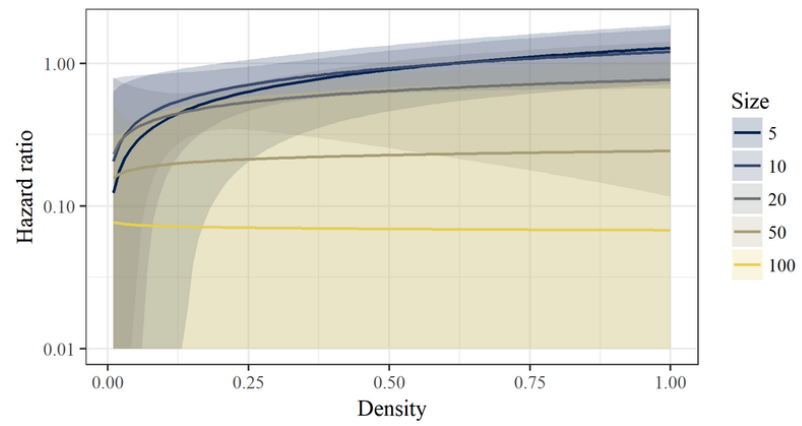

a Shaded regions represent the 95\% confidence interval. 


\section{Figure 4. Interaction Effect Between Groups' E-I Index and Edges on Group Persistence ${ }^{a}$}

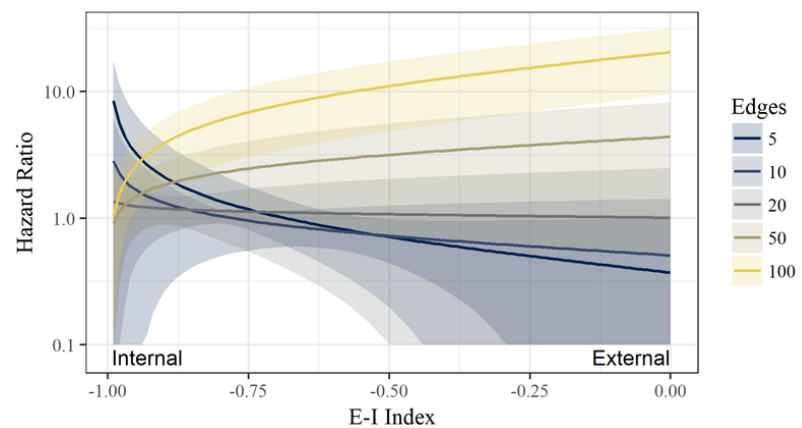

a Shaded regions represent the 95\% confidence interval.

\section{Table 1. Summary Statistics}

\begin{tabular}{|c|c|c|c|c|c|}
\hline Variables & Mean & SD & Minimum & Maximum & $\mathrm{Rho}^{\mathrm{a}}$ \\
\hline Duration & 1.49 & .72 & 1 & 3 & \\
\hline Ln Size & 2.05 & 1.15 & 1.1 & 5.65 & $.58^{* * *}$ \\
\hline Period & 1.68 & .65 & 1 & 3 & $.32 * * *$ \\
\hline Months & 19.32 & 7.87 & .37 & 35.53 & -.06 \\
\hline Haitian & .57 & .31 & 0 & 1 & $-.10 *$ \\
\hline Removed & .04 & .10 & 0 & 0.67 & $.27^{* * *}$ \\
\hline \multicolumn{6}{|c|}{ Criminality } \\
\hline $\begin{array}{l}\text { Violent } \\
\text { offenses }\end{array}$ & .28 & .27 & 0 & 1 & .00 \\
\hline $\begin{array}{l}\text { Property } \\
\text { offenses }\end{array}$ & .14 & .19 & 0 & 1 & $.18^{* * *}$ \\
\hline $\begin{array}{l}\text { Market } \\
\text { offenses }\end{array}$ & .05 & .13 & 0 & 1 & $.31^{* * *}$ \\
\hline
\end{tabular}




\begin{tabular}{|c|c|c|c|c|c|}
\hline $\begin{array}{l}\text { Drug use } \\
\text { offenses }\end{array}$ & .04 & .08 & 0 & 1 & $.42^{* * *}$ \\
\hline Other offenses & .41 & .29 & 0 & 1 & $.24 * * *$ \\
\hline $\begin{array}{l}\text { Ln } \\
\text { Productivity }\end{array}$ & 1.04 & 0.63 & 0 & 3.95 & $.33^{* * *}$ \\
\hline Age range & 13.47 & 13.01 & 0 & 53 & $.47^{* * *}$ \\
\hline \multicolumn{6}{|l|}{ Cohesion } \\
\hline Density & .55 & .34 & .02 & 1 & $-.58 * * *$ \\
\hline E-I Index & -.98 & .05 & -1 & -.72 & $.64 * * *$ \\
\hline Ln Edges & 2.21 & 1.44 & .69 & 6.59 & $.55^{* * *}$ \\
\hline Ln Alliances & .40 & .78 & 0 & 2.94 & $.66^{* * *}$ \\
\hline \multicolumn{6}{|l|}{$\begin{array}{l}\text { No. } \\
\text { Observations: } \\
410\end{array}$} \\
\hline $\begin{array}{l}\text { No. Groups: } \\
327\end{array}$ & & & & & \\
\hline
\end{tabular}

ABBREVIATIONS: $\mathrm{SD}=$ Standard Deviation

a Bivariate tests represent the Spearman's Rho for the relationship between the outcome (group duration) and each covariate.

${ }^{*} \mathrm{p}<.05 ;{ }^{* *} \mathrm{p}<.01 ;{ }^{* * *} \mathrm{p}<.001$ (two-tailed)

\section{Table 2. Discrete Event History Models Predicting Criminal Group Persistence $^{\mathrm{a}, \mathrm{b}}$}

\begin{tabular}{|l|l|l|l|l|l|l|l|l|}
\hline & Model 1 & Model 2 & Model 3 & & \\
\hline $\begin{array}{l}\text { Variable } \\
\text { s }\end{array}$ & HR & & $95 \%$ CI & HR & 95\% CI & HR & $95 \%$ CI \\
\hline
\end{tabular}




\begin{tabular}{|c|c|c|c|c|c|c|c|c|c|}
\hline Ln size & 0.58 & $* * *$ & $\begin{array}{l}(0.52- \\
0.64)\end{array}$ & .27 & $* * *$ & $\begin{array}{l}(0.15- \\
0.50)\end{array}$ & 0.35 & $* *$ & $\begin{array}{l}(0.18- \\
0.71)\end{array}$ \\
\hline Period & 1.21 & * & $\begin{array}{l}(1.03- \\
1.42)\end{array}$ & 1.22 & * & $\begin{array}{l}(1.04- \\
1.43)\end{array}$ & 1.20 & $*$ & $\begin{array}{l}(1.03- \\
1.40)\end{array}$ \\
\hline Months & 0.99 & & $\begin{array}{l}(0.99- \\
1.00)\end{array}$ & .99 & & $\begin{array}{l}(0.99- \\
1.00)\end{array}$ & 0.99 & $*$ & $\begin{array}{l}(1.00- \\
1.00)\end{array}$ \\
\hline Haitian & 0.91 & & $\begin{array}{l}(0.69- \\
1.19)\end{array}$ & .91 & & $\begin{array}{l}(0.70- \\
1.20)\end{array}$ & 0.92 & & $\begin{array}{l}(0.70- \\
1.21)\end{array}$ \\
\hline $\begin{array}{l}\text { Remove } \\
\text { d }\end{array}$ & 1.82 & * & $\begin{array}{l}(1.15- \\
2.90)\end{array}$ & 1.75 & * & $\begin{array}{l}(1.11- \\
2.75)\end{array}$ & 1.67 & $*$ & $\begin{array}{l}(1.08- \\
2.59)\end{array}$ \\
\hline $\begin{array}{l}\text { Crimina } \\
\text { lity }^{\mathrm{C}}\end{array}$ & & & & & & & & & \\
\hline $\begin{array}{l}\text { Propert } \\
\text { y } \\
\text { offenses }\end{array}$ & 0.99 & & $\begin{array}{l}(0.69- \\
1.41)\end{array}$ & 1.01 & & $\begin{array}{l}(0.70- \\
1.44)\end{array}$ & 0.99 & & $\begin{array}{l}(0.69- \\
1.43)\end{array}$ \\
\hline $\begin{array}{l}\text { Market } \\
\text { offenses }\end{array}$ & 1.22 & & $\begin{array}{l}(0.80- \\
1.85)\end{array}$ & 1.10 & & $\begin{array}{l}(0.73- \\
1.66)\end{array}$ & 1.12 & & $\begin{array}{l}(0.73- \\
1.70)\end{array}$ \\
\hline $\begin{array}{l}\text { Drug } \\
\text { use } \\
\text { offenses }\end{array}$ & 0.91 & & $\begin{array}{l}(0.38- \\
2.17)\end{array}$ & .97 & & $\begin{array}{l}(0.39- \\
2.40)\end{array}$ & 0.97 & & $\begin{array}{l}(0.42- \\
2.22)\end{array}$ \\
\hline $\begin{array}{l}\text { Other } \\
\text { offenses }\end{array}$ & 0.89 & & $\begin{array}{l}(0.66- \\
1.19)\end{array}$ & .90 & & $\begin{array}{l}(0.67- \\
1.20)\end{array}$ & 0.88 & & $\begin{array}{l}(0.65- \\
1.19)\end{array}$ \\
\hline $\begin{array}{l}\text { Ln } \\
\text { product } \\
\text { ivity }\end{array}$ & 0.90 & & $\begin{array}{l}(0.78- \\
1.03)\end{array}$ & .92 & & $\begin{array}{l}(0.80- \\
1.06)\end{array}$ & 0.93 & & $\begin{array}{l}(0.81- \\
1.07)\end{array}$ \\
\hline $\begin{array}{l}\text { Age } \\
\text { range }\end{array}$ & & & & 1.01 & & $\begin{array}{l}(1.00- \\
1.02)\end{array}$ & 1.01 & & $\begin{array}{l}(1.00- \\
1.02)\end{array}$ \\
\hline $\begin{array}{l}\text { Cohesio } \\
\mathrm{n}^{\mathrm{d}}\end{array}$ & & & & & & & & & \\
\hline
\end{tabular}




\begin{tabular}{|c|c|c|c|c|c|c|c|c|c|}
\hline $\begin{array}{l}\text { Ln } \\
\text { edges }\end{array}$ & & & & 1.67 & * & $\begin{array}{l}(1.05- \\
2.65)\end{array}$ & 1.56 & & $\begin{array}{l}(0.93- \\
2.62)\end{array}$ \\
\hline $\begin{array}{l}\text { Ln } \\
\text { alliance } \\
\text { s }\end{array}$ & & & & 1.19 & & $\begin{array}{l}(0.90- \\
1.57)\end{array}$ & .76 & & $\begin{array}{l}(0.46- \\
1.23)\end{array}$ \\
\hline $\begin{array}{l}\text { Ln } \\
\text { edges } \times \\
\text { Ln size }\end{array}$ & & & & & & .74 & $*$ & $\begin{array}{l}(0.56- \\
0.99)\end{array}$ & \\
\hline $\begin{array}{l}\text { Ln } \\
\text { edges } \times \\
\text { Ln } \\
\text { alliance } \\
\text { s }\end{array}$ & & & & & & 1.54 & $*$ & $\begin{array}{l}(1.11- \\
2.15)\end{array}$ & \\
\hline LL & $\begin{array}{l}- \\
1528.18 \\
* * *\end{array}$ & $\begin{array}{l}- \\
1526.13 \\
\text { *** }\end{array}$ & $\begin{array}{l}- \\
1523.80 \\
* * *\end{array}$ & & & & & & \\
\hline AIC & $\begin{array}{l}3076.37 \\
* *\end{array}$ & $\begin{array}{l}3078.26 \\
* *\end{array}$ & $\begin{array}{l}3077.59 \\
* *\end{array}$ & & & & & & \\
\hline BIC & $\begin{array}{l}3116.53 \\
* *\end{array}$ & $\begin{array}{l}3130.47 \\
* *\end{array}$ & $\begin{array}{l}3137.84 \\
* *\end{array}$ & & & & & & \\
\hline
\end{tabular}

ABBREVIATIONS: $\mathrm{HR}$ = hazard ratio; $\mathrm{CI}=$ confidence intervals; $\mathrm{LL}=$ log-likelihood; $\mathrm{AIC}=$ Akaike information criterion, $\mathrm{BIC}=$ Bayesian information criterion

a N observations: 410; N groups: 327

$\mathrm{b} \mathrm{HR}=\exp (b)$

c Reference category: Violent offenses

d Cohesion variables have been standardized

$* \mathrm{p}<.05 ;{ }^{* *} \mathrm{p}<.01 ;{ }^{* * *} \mathrm{p}<.001$ (two-tailed)

\section{Appendix}




\section{Table A. Community Validation}

\begin{tabular}{|c|c|c|c|}
\hline Indicators & Uncertainty Coefficient & $\mathrm{Chi}^{2}$ (df) & \\
\hline $\begin{array}{l}\text { Broad gang allegiance } \\
\text { ('red' or 'blue') }\end{array}$ & .10 & $805.06(235)$ & $* * *$ \\
\hline $\begin{array}{l}\text { Specific gang } \\
\text { allegiance (gang name) } \\
\text { a }\end{array}$ & .50 & $16661.24(11400)$ & $* * *$ \\
\hline Age & .07 & 5921.69 (1617) & $* * *$ \\
\hline Number of Offenses & .03 & 2355.01 (1078) & $* * *$ \\
\hline \multicolumn{4}{|c|}{$* \mathrm{p}<.05 ; * * \mathrm{p}<.01 ; * * * \mathrm{p}<.001$ (two-tailed) } \\
\hline \multicolumn{4}{|c|}{$\begin{array}{l}\text { a Of the } 540 \text { gang members for which their specific gang membership was known, } 12 \\
\text { percent had more than one gang listed and } 2 \text { percent three gangs listed. The analyses } \\
\text { were rerun using different combinations of gang allegiance. Results are consistent } \\
\text { with those presented above. }\end{array}$} \\
\hline
\end{tabular}

\section{Footnotes}

1. This approach is analogous to snowball sampling, a strategy previously used by scholars to gather data on gang members and group processes (e.g. Decker, 1996).

2. We applied a variety of community detection algorithms including GirvanNewman (Girvan and Newman, 2007) and Newman (Clauset, Newman, and Moore, 2004) selecting the Louvain, as it had the highest modularity coefficient. $\subseteq$

3. There is no agreed upon operationalization of durability; with, 'several months' suggested as a guideline (Klein, Weerman, and Thornberry, 2006). 4. For the 583 individuals identified as known gang members, information on whether the individual belonged to one of two broad gang affiliations (the 'red' or 'blues') was provided. In addition, for 540 of these individuals, information on their specific gang name, comprising 78 unique police-recorded gangs, was also provided. To validate whether the groups in our sample, identified through community detection methods, reflected these gang structures we ran a series of 
bivariate tests. Results, reported in the Appendix (Table A), showed that the partitioning of members into communities reflected some of the divisions in the larger gang affiliation (i.e. reds vs blues); as well as divisions in membership according to the 78 police-reported gangs. $\_$

5. A group split into two or more factions in $29 \%$ of the cases from $2001-2003$ to 2004-2006 and 33\% of the cases from 2004-2006 to 2007-2009.

6. For our measure of alliances, we also reran our models distinguishing between co-offending alliances (members of different groups who co-offended together) and police-stop alliances (members of different groups who were recorded as present together during a police stop). All substantive results remained the same. $\subseteq$

7. We also reran the analysis to include a measure of conflict relationships (operationalized as members of two respective groups being involved in an offense together, where one group's member(s) was recorded as the victim, and the other group's member(s) as the perpetrator). However, the results did not show any significant relationships between conflict, regardless as to whether it was included as a binary or continuous variable (or directed or undirected) and group survival, and we do not include them in the final models. We return to the this in the discussion on our sample and the potentially unique context of Montreal gangs. $\uplus$

8. In a separate analysis, we substituted our measure of age range with age variance; however, the results remained consistent. $\_$

9. Recall that density and the E-I Index represent the ratios for edges and alliances, respectively. Although the models only include the direct effects for each measure (i.e. edges and alliances), for ease of interpretation we plot the interactions using the ratios. Density is calculated as [edges / ( $\operatorname{size}-1 *$ size) / 2)] and the E-I index as [(External-ties - Internal-ties) / (External-ties + Internalties)].

10. Information on gang membership was provided for 21 percent of individuals one-step from the seeds, and five percent of individuals two-steps from the seeds. For individuals one-step, 76 percent were identified as non-gang members, and, for individuals two-steps away, 92 percent were identified as non-gang members. $\triangleq$ 